Article

\title{
New Epoxy Thermosets Organic-Inorganic Hybrid Nanomaterials Derived from Imidazolium Ionic Liquid Monomers and POSS ${ }^{\circledR P h}$
}

\author{
Houssém Chabane ${ }^{1,2}{ }^{\oplus}$, Sébastien Livi ${ }^{1}$, Jannick Duchet-Rumeau ${ }^{1}$ and Jean-François Gérard ${ }^{1, *}$ \\ 1 Univ Lyon, CNRS, UMR 5223, Ingénierie des Matériaux Polymères, Université Claude Bernard Lyon 1, \\ INSA Lyon, Université Jean Monnet, F-69621 Villeurbanne, France; houssem.chabane@insa-lyon.fr (H.C.); \\ sebastien.livi@insa-lyon.fr (S.L.); jannick.duchet@insa-lyon.fr (J.D.-R.) \\ 2 Laboratoire de Chimie Macromoléculaire, Ecole Militaire Polytechnique, BP 17, Bordj El-Bahri, \\ 16111 Algiers, Algeria \\ * Correspondence: jean-francois.gerard@insa-lyon.fr; Tel.: +33-0472436004
}

Citation: Chabane, H.; Livi, S.; Duchet-Rumeau, J.; Gérard, J.-F. New Epoxy Thermosets Organic-Inorganic Hybrid Nanomaterials Derived from Imidazolium Ionic Liquid Monomers and POSS ${ }^{\circledR P h}$. Nanomaterials 2022, 12, 550. https://doi.org/10.3390/nano 12030550

Academic Editor: Ana B. Pereiro

Received: 26 December 2021

Accepted: 3 February 2022

Published: 6 February 2022

Publisher's Note: MDPI stays neutral with regard to jurisdictional claims in published maps and institutional affiliations.

Copyright: (C) 2022 by the authors. Licensee MDPI, Basel, Switzerland. This article is an open access article distributed under the terms and conditions of the Creative Commons Attribution (CC BY) license (https:// creativecommons.org/licenses/by/ $4.0 /)$.

\begin{abstract}
New epoxy-amine networks issue from epoxydized imidazolium ionic liquid monomers (ILMs) and isophorone diamine (IPD) were modified for the first time by incorporating unmodified trisilanol phenyl POSS ${ }^{\circledR}$ (POSS ${ }^{\circledR P h}$-triol) and two ionic liquid-modified POSS ${ }^{\circledR P h}$ (IL-g-POSS ${ }^{\circledR P h}$ ) having chloride $\left(\mathrm{Cl}^{-}\right)$and bis-trifluoromethanesulfonimidate $\left(\mathrm{NTf}_{2}{ }^{-}\right)$counter anions. Then, $5 \mathrm{wt} . \%$ of unmodified and IL-modified POSS ${ }^{\circledR P h}$ were introduced in order to develop new solid electrolytes. First, a homogeneous dispersion of the POSS ${ }^{\circledR P h}$ aggregates (diameters from 80 to $400 \mathrm{~nm}$ ) into epoxy networks was observed. As a consequence, ILM/IPD networks with glass transition temperatures between 45 and $71^{\circ} \mathrm{C}$ combined with an enhancement of the thermal stability $\left(>380^{\circ} \mathrm{C}\right)$ were prepared. Moreover, a significant increase of the hydrophobic character and high oil repellency of the network surfaces were obtained by using IL-g-POSS ${ }^{\circledR P h}\left(19-20 \mathrm{~mJ} \cdot \mathrm{m}^{-2}\right)$, opening up promising prospects for surface coating applications. Finally, these new epoxy networks exhibited outstanding high ionic conductivities (from $3.4 \times 10^{-8}$ to $6.8 \times 10^{-2} \mathrm{~S} . \mathrm{m}^{-1}$ ) combined with an increase in permitivity.
\end{abstract}

Keywords: diepoxydized ionic liquid; polyhedral oligomeric silsesquioxane (POSS ${ }^{\circledR}$ ); epoxy networks; ionic conductivity

\section{Introduction}

In recent years, numerous works have reported on the design of new electrolytes in order to propose alternatives to liquid electrolytes containing organic solvents, i.e., to ensure the safety of the installations, avoiding leakage of liquids and related explosions [1-4]. Among these, two strategies were proposed focusing on the development of polymer electrolytes including solid polymer electrolytes (SPEs) and gel polymer electrolytes (GPEs) [4,5]. Solid polymer electrolytes (SPEs) are considered as the best alternative to solve safety issues, combined with an improvement of the mechanical behavior and capability of holding liquid electrolytes, as well as to obtain high ionic conductivity with good electrochemical stability [6,7]. However, there is still work to be undertaken before finding ideal solid polymer electrolytes that respect all the parameters required at the same time-i.e., high ionic conductivity, excellent electrochemical stability, low interfacial resistance between electrode and electrolyte, good mechanical integrity, high thermal stability, etc. These requirements have not been concurrently fulfilled to enable practical electrolyte applications [8,9]. Various SPEs combined with high $\mathrm{Li}^{+}$conductivity have been developed [6,10-12]. Polyethylene oxide (PEO) incorporated with Li salts [13] was the first $\mathrm{SPE}$ reported in the literature, where the transport of $\mathrm{Li}^{+}$ions was affected by the number of free $\mathrm{Li}^{+}$ions and their displacement capacity. Yuan et al. [14] reported a high ionic conductivity of $3.16 \times 10^{-5} \mathrm{~S} \mathrm{~cm}^{-1}$ at $25^{\circ} \mathrm{C}$ by incorporation of Zn-based MOF-5 into 
PEO-based composite polymer electrolytes using in situ method [14]. Gerbaldi et al. [15] also achieved high performance SPE for Li-based batteries by using aluminum-based MOFs (Al-BTC MOFs) dispersed in a PEO matrix [15]. However, despite their high ionic conductivity value, these SPEs have many disadvantages such as lower mechanical properties, a reduced electrochemical stability window, a poor charge-discharge stability and unfavorable interface contacts with the electrodes. In addition, their difficult processing conditions considerably limit their applications [16,17].

The main advantages of polyepoxides for electrical applications are their low relative permittivity (typically three to six), their low losses and dissipation, their excellent dielectric strength (can reach $180 \mathrm{kV} / \mathrm{mm}$ in DC) as well as their low conductivity (from $10^{-12}$ to $10^{-19} \mathrm{~S} / \mathrm{m}$ ). As a result, polyepoxides are widely used and studied as insulators, and only few works have reported the conduction mechanisms of these systems. On the other hand, the conduction mechanisms have been widely investigated in the field of ionic conductive polymers, namely electrolyte polymers. Due to their good chemical stability and high ionic conductivity, ionic liquids are good candidates $[16,17]$. Ionic liquids (ILs) are salts composed of ammonium, imidazolium or even phosphonium cations, and combined with organic or inorganic anions with a low melting temperature. One of their advantages is their great versatility that can induce good chemical and thermal stabilities, as well as significant ionic conductivity. These properties make them, for example, interesting as a lubricant, electrolyte or additive in polymer science [12-17]. The association of ionic liquids with polyepoxides has been studied in the literature for use as an initiator and/or catalyst for the polymerization of epoxies, but also as a solution for electrolyte applications. Polymerized ionic liquids (PILs) combine both the properties of ILs (wide electrochemical window, non-volatility, and tunable molecular design) and of polymers (avoiding liquid leakage, no need of a separator, mechanical performances, and easier implementation) [18]. Recently, PILs prepared by polyaddition have been preferred for preparing SPEs to get over the challenges and limitations of conventional two-ion conductive SPEs [12-17]. Various PILs based on imidazolium have been considered in the literature [18-21]. The majority of these studies involved mono-cationic PIL-based electrolytes displaying significant ionic conductivities by using large contents of ionic liquids (from 10 to $90 \mathrm{wt}$ \%) for temperatures ranging from 50 to $100^{\circ} \mathrm{C}$ [22-25]. For example, Obadia et al. [23] have prepared a series of anionic poly(ionic liquid)s with 1,2,3-triazolium counter cations by cation exchange between tailormade 1,3,4-trialkylated-1,2,3-triazolium iodides and a polystyrene derivative having as side chain potassium groups bis-(trifluoromethylsulfonyl)imide ones. The resulting PILs networks showed a great potential for applications that require solid electrolytes with ionic conductivities from $7.8 \times 10^{-8}$ to $8.4 \times 10^{-7} \mathrm{~S}^{-m^{-1}}$ at $30^{\circ} \mathrm{C}[22,23]$. Other authors proposed materials having an ionic conductivity of $8.6 \times 10^{-9} \mathrm{~S} . \mathrm{m}^{-1}$ at $30{ }^{\circ} \mathrm{C}$ by combining $10 \mathrm{wt}$ \% of IL electrolyte with poly(diallyldimethylammonium) bis(trifluoromethanesulfonyl)imide (PDADMA TFSI) [26,27]. Ionic conductivity higher than $10^{-5} \mathrm{~S} . \mathrm{m}^{-1}$ at the same temperature was obtained by increasing the IL content up to 40 wt.\% [25]. Recently, Porcarelli et al. [24] synthesized different types of methacrylic ILMs monomers copolymerized with poly(ethylene glycol) methyl ether methacrylate (PEGM) via conventional free radical reaction. The resulting solid polymer electrolytes showed high ionic conductivities (up to $1.9 \times 10^{-6}$ and $2 \times 10^{-5} \mathrm{~S} . \mathrm{m}^{-1}$ at 25 and $70^{\circ} \mathrm{C}$, respectively) combined with a low $\mathrm{T}_{\mathrm{g}}$ (from -61 to $-27^{\circ} \mathrm{C}$ ) depending on copolymer composition and ILM/PEGM ratio [24]. Solid polymer electrolytes having a $\mathrm{T}_{\mathrm{g}}$ close to room temperature showed a very low conductivity (lower than $10^{-11} \mathrm{~S} . \mathrm{m}^{-1}$ ) [24]. Livi et al. [28] obtained (multi)functional epoxy ionic liquid networks from the copolymerization between an imidazolium ionic liquid monomer and conventional polyether-amine (Jeffamine D230) which has a high ionic conductivity of about $7.39 \times 10^{-8}$ and $4 \times 10^{-4} \mathrm{~S}^{-1} \mathrm{~m}^{-1}$ at 30 and $70^{\circ} \mathrm{C}$, respectively.

Very recently, POSS ${ }^{\circledR}$-based materials were described which can enhance the thermal and electrochemical stabilities of SPEs due to their unique structure and the fact that their inner inorganic silicon oxygen core facilitates ion conduction $[29,30]$. The incorporation of 
POSS $^{\circledR}$ nanoclusters in an epoxy-based matrix allows for the enhancement of oxidative and thermal resistances [31-33], surface characters (such as adhesion and wettability) [34,35], combustion performances [33], and dielectric as well as mechanical properties [36,37]. POSS $^{\circledR}$ nanoclusters can be used for designing solid polymer electrolytes for lithium batteries and fuel cells [38-40]. Gyu et al. [29] described nanomaterials prepared from of polyethylene oxide (PEO)/polyethylene glycol-polyhedraoligomeric silsesquioxane (PEGPOSS $^{\circledR}$ ) combinations which exhibit enhanced ionic conductivity (from $1.19 \times 10^{-5}$ to $1.27 \times 10^{-4} \mathrm{~S} . \mathrm{cm}^{-1}$ ). Lu et al. [30] also obtained crosslinked polymer membranes (3D-PEs) with star-shaped structures having ionic conductivity up to $2.35 \times 10^{-3}{\mathrm{~S} . \mathrm{cm}^{-1}}^{1}$ at room temperature with the introduction of a multifunctional epoxy POSS ${ }^{\circledR}$. These authors also observed that the most of the POSS ${ }^{\circledR}$-epoxy networks display higher real and imaginary parts of the complex permittivity compared to the ones of the neat epoxy network. Recently, some researchers have reported the grafting of ionic liquids onto octa-silsesquioxane (IL-g-POSS ${ }^{\circledR}$ ) and investigated if they could be useful to prepare new solid electrolytes polymers [41,42]. The grafting of ionic liquids onto POSS ${ }^{\circledR}[41,42]$ has shown a strong improvement of ionic conductivity, excellent electrochemical stability, and high thermal stability compared to systems which only contain POSS ${ }^{\circledR}$ [38-40] or POSS ${ }^{\circledR}$ with free ionic liquid [43]. Our previous studies reported also that the connection of ion pairs to POSS ${ }^{\circledR P h}$ with different organic ligands (isobutyl or phenyl) can significantly help to improve the $\mathrm{O} / \mathrm{I}$ interphase and promote the formation of well-dispersed POSS ${ }^{\circledR}$ nanodomains [44] leading to nanomaterials with outstanding thermal and mechanical properties [45]. From these previous results and the ones reported in the literature, it is plausible that a new generation of electrolyte could be designed. In addition, novel epoxy-functionalized monoimidazolium or bis-imidazolium ionic liquid monomers have been synthesized in our group to substitute the bisphenol A diglycidyl ether prepolymer (DGEBA) as starting components [46,47]. Moreover, to the best of our knowledge, there is no work investigating the effect of IL grafted POSS ${ }^{\circledR}$ introduction into epoxy PILs.

In the present work, a new generation of nanostructured epoxy PILs is prepared by combining POSS $^{\circledR}$ and ionic liquid monomers. For this, two types of epoxy ionic liquid monomers (ILM1 and ILM2) based on imidazolium salt have been synthesized as well as three types of POSS ${ }^{\circledR P h} \mathrm{O} / \mathrm{I}$ nanoclusters $\left(\mathrm{POSS}^{\circledR P h}\right.$-triol and IL-g-POSS ${ }^{\circledR P h}$ with different anions). First, the influence of these epoxy ionic liquid monomers structure on the dispersion morphology of POSS ${ }^{\circledR P h}$ was investigated based on transmission electron microscopy (TEM). Then, the thermal properties (DSC, TGA), surface properties, and the ionic conductivity behavior of these new hybrid $\mathrm{O} / \mathrm{I}$ nanomaterials have been investigated and compared with conventional DGEBA-IPD networks.

\section{Materials and Characterization Methods}

\subsection{Materials}

All reagents purchased from Sigma Aldrich Co (St. Louis, MO, USA)., or TCI Co (Paris, France). were used as received. Solvents were used in RPE grade without further purification. Anhydrous solvents were obtained from a Puresolv SPS400 apparatus developed by Innovative Technology Inc. (Hong Kong, China) Epoxy prepolymer based on diglycidyl ether of bisphenol A (DGEBA), denoted Epon 828, was provided from Hexion Co (Louvain-la-Neuve, Belgium). The isophorone diamine (IPD), from Aldrich Co. (St. Louis, MO, USA), was used as hardener with epoxy ionic liquid monomers (ILM1 or ILM2), commercial epoxy prepolymer DGEBA. Heptaphenyl-trisilanol POSS ${ }^{\circledR P h}$, denoted POSS ${ }^{\circledR P h}$-triol, from Hybrid Plastics Co (Hattiesburg, MS, USA). was used as received. All the chemical formulae of components used are summarized in Table 1. 
Table 1. Chemical formula of components used to design nanostructured epoxy-amine networks.

\begin{tabular}{c}
\hline Name \\
$\begin{array}{c}\text { Diglycidyl ether of } \\
\text { bisphenol A } \\
\text { (DGEBA) }\end{array}$ \\
3-[2-(oxiran-2-yl)ethyl]-1-[6,7]imidazolium \\
1,1,1-trifluoroN- \\
[(trifluoromethyl)sulfonyl]methanesulfonamide \\
3,3'-(1,4-butanediyl)bis \\
[1-(4-(2-(oxiran-2-yl)ethyl)phenyl)]imidazolium \\
1,1,1-trifluoro- $N$ -
\end{tabular}

ILM2

Isophoronediamine

(IPD)

Heptaphenyl-trisilanol POSS ${ }^{\circledR}$ (POSS $^{\text {Ph }}$-triol)

1-methyl-3-propyl heptaphenyl octasilesquioxane imidazolium chloride (IL.Cl-g-POSS ${ }^{\circledR P h}$ )

1-methyl-3-propyl heptaphenyl octasilesquioxane imidazolium bis(trifluoromethane)sulfonimide (IL.NTf ${ }_{2}$-g-POSS ${ }^{\circledR P h}$ )
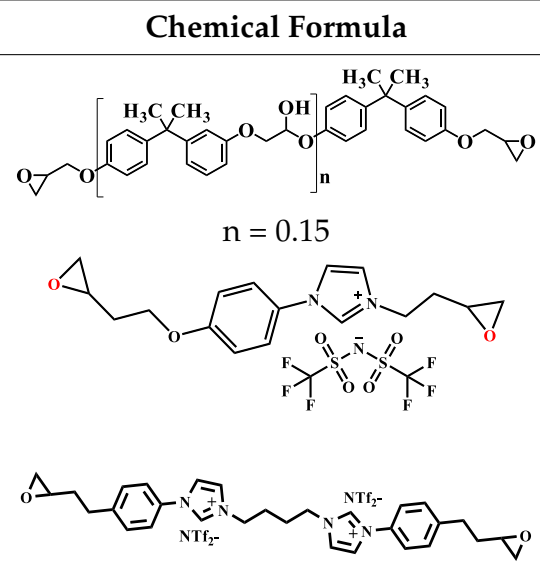<smiles>CC1(C)CC(N)CC(C)(CN)C1</smiles><smiles>ON(ONc1ccccc1)N(c1ccccc1)c1ccccc1</smiles>

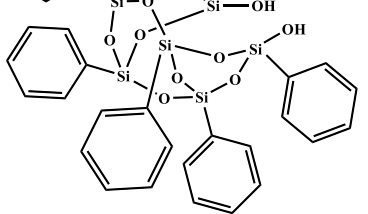

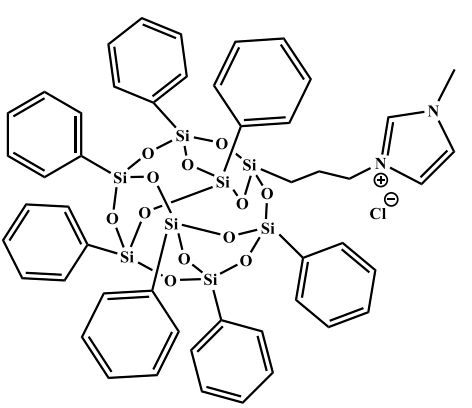

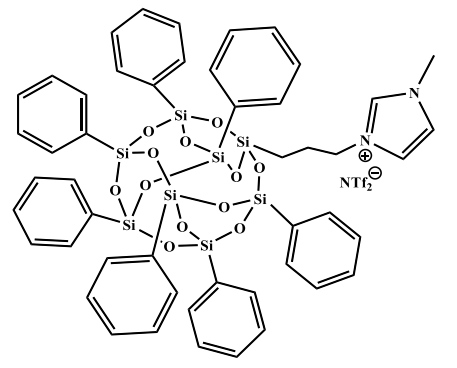

\section{Characteristics}

377 g.mol ${ }^{-1}$, eew: $185-192 \mathrm{~g} / \mathrm{eq}^{\mathrm{a}}$,

$\mathrm{T}_{\mathrm{g}}=-13^{\circ} \mathrm{C}^{\mathrm{b}}$,

$\mathrm{T}_{\mathrm{d}}=330^{\circ} \mathrm{C}^{\mathrm{b}}$

Prepared following published procedure [28] $\mathrm{T}_{\mathrm{d}}=489^{\circ} \mathrm{C}^{\mathrm{b}}$

Prepared following published procedure [46]

$\mathrm{T}_{\mathrm{m}}=71^{\circ} \mathrm{C}^{\mathrm{a}}$ $\mathrm{T}_{\mathrm{d}}=460^{\circ} \mathrm{C}^{\mathrm{b}}$

$\mathrm{M}=170.3 \mathrm{~g} \cdot \mathrm{mol}^{-1}$

$\mathrm{M}=931.34 \mathrm{~g} \mathrm{~mol}^{-1}$

$\mathrm{T}_{\mathrm{m} 1}=217^{\circ} \mathrm{C}^{\mathrm{a}}$,

$\mathrm{T}_{\mathrm{m} 2}=230^{\circ} \mathrm{C}^{\mathrm{a}}$,

$\mathrm{T}_{\mathrm{d}}=632{ }^{\circ} \mathrm{C}^{\mathrm{b}}$

Prepared following the procedure reported in [45]

$\mathrm{M}=1116.04 \mathrm{~g} \mathrm{~mol}^{-1}$,

$\mathrm{T}_{\mathrm{m} 1}=127^{\circ} \mathrm{C}^{\mathrm{a}}$,

$\mathrm{T}_{\mathrm{m} 2}=168^{\circ} \mathrm{C}^{\mathrm{a}}$,

$\mathrm{T}_{\mathrm{d}}=632{ }^{\circ} \mathrm{C}^{\mathrm{b}}$

Prepared following the procedure reported in [45]

$\mathrm{M}=1360.73 \mathrm{~g} \mathrm{~mol}^{-1}$,

$\mathrm{T}_{\mathrm{m} 1}=135^{\circ} \mathrm{C}^{\mathrm{a}}$

$\mathrm{T}_{\mathrm{m} 2}=158^{\circ} \mathrm{C}^{\mathrm{a}}$,

$\mathrm{T}_{\mathrm{d}}=534^{\circ} \mathrm{C}^{\mathrm{b}}$

${ }^{a} \mathrm{~T}_{\mathrm{m}}$ : Melting temperature, ${ }^{\mathrm{b}} \mathrm{T}_{\mathrm{d}}$ : Degradation temperature determined at the maximum of the first derivative of the weight loss as a function of temperature.

\subsection{Epoxy Network Preparation}

To prepare epoxy-amine networks, epoxy prepolymer (DGEBA) or epoxy ionic liquid monomers (ILM1 or ILM2) (see Table 1) were mixed with the isophoronediamine (IPD) used as co-monomer under mechanical stirring with a stoichiometric ratio amino hydrogen-toepoxy equal to 1 . For the POSS ${ }^{\circledR P h}$-modified epoxy networks, the $5 \mathrm{wt} . \%$ of POSS ${ }^{\circledR P h}$-triol 
or IL-g-POSS ${ }^{\circledR P h}$ were premixed in the DGEBA epoxy prepolymer or the epoxy ionic liquid monomers (ILM1 or ILM2) at $100{ }^{\circ} \mathrm{C}$ for $45 \mathrm{~min}$ in order to obtain a homogeneous and transparent solution before adding the isophoronediamine. Then, the mixture was degassed and poured into molds. Finally, the different systems were polymerized under different conditions: $i$ / The neat epoxy-amine and the POSS ${ }^{\circledR P h}$-modified epoxy based on ILM2 networks were cured for $1 \mathrm{~h}$ at $140^{\circ} \mathrm{C}$ and post-cured for $8 \mathrm{~h}$ at $190^{\circ} \mathrm{C}$ whereas the other system based on ILM1 was cured for $3 \mathrm{~h}$ at $80{ }^{\circ} \mathrm{C}$ and $6 \mathrm{~h}$ at $120^{\circ} \mathrm{C}$, followed by a post-curing process at $200{ }^{\circ} \mathrm{C}$ for $1 \mathrm{~h}$ in order to ensure a complete crosslinking of the resulting networks.

\subsection{Determination of the Soluble Fraction Obtained from Hybrid O/I Networks}

The solubilization was considered to determine the POSS ${ }^{\circledR P h}$ fraction covalently bonded to the architecture of the networks. The extraction was undertaken using THF at $60{ }^{\circ} \mathrm{C}$ for $24 \mathrm{~h}$ and the THF was removed by evaporation using rotary evaporator. The soluble fraction, $w_{s}$, was evaluated from the weight of the dry sample before, $m_{d r y}$, and after extraction $\left(m_{d r y-e x t}\right)$ using the following equation:

$$
\left.\mathrm{w}_{\mathrm{s}}=1-\left(\mathrm{m}_{\text {dry-ext }}\right) / \mathrm{m}_{\text {dry }}\right)
$$

\subsection{Characterization Methods}

Fourier Transform Infrared Absorption Spectra (FTIR) were recorded using a Thermo Scientific Nicolet iS10 spectrometer in attenuated total reflectance (ATR) mode from 4000 to $500 \mathrm{~cm}^{-1}$ (32 scans, resolution $4 \mathrm{~cm}^{-1}$ ) used to identify the soluble fraction obtained from the solubilization of the hybrid $\mathrm{O} / \mathrm{I}$ networks in the THF. In addition, the reaction kinetics, i.e., the quantification of the epoxide groups conversion, for all the reactive systems were investigated by FT-IR spectroscopy following the curing conditions: $3 \mathrm{~h}$ at $80^{\circ} \mathrm{C}, 6 \mathrm{~h}$ at $120^{\circ} \mathrm{C}$, and $1 \mathrm{~h}$ at $200{ }^{\circ} \mathrm{C}$ for ILM1/IPD and $1 \mathrm{~h}$ at $140{ }^{\circ} \mathrm{C}$ followed by $8 \mathrm{~h}$ at $190{ }^{\circ} \mathrm{C}$ for ILM2/IPD. All the reactive systems were analyzed in the wavelength region of 800$1300 \mathrm{~cm}^{-1}$ in order to follow the changes of the adsorption bands at 914 and $1132 \mathrm{~cm}^{-1}$ corresponding to the epoxy groups with reference as the absorption band at $1132 \mathrm{~cm}^{-1}$ (trifluoromethyl $\left(-\mathrm{CF}_{3}\right)$ of bis(trifluoromethanesulfonyl)imidate counterions $\left(\mathrm{NTf}_{2}{ }^{-}\right)$[46], respectively, by using the following equation [28,45,46]:

$$
\mathrm{X} \%=\frac{A_{0}-A_{t}}{A_{t}} \times 100 \%
$$

where $A_{0}$ and $A_{t}$ are the ratios between the area of two absorption bands at 914 and $1132 \mathrm{~cm}^{-1}\left(A_{914} / A_{1132}\right)$ of the reactive system at the beginning of the reaction $(t=0)$ and at a given reaction time $t$. Thus, the epoxy conversion versus the polymerization time is presented in Figure S2a and S2b.

${ }^{13} \mathrm{C}$ HR-MAS NMR spectroscopy analyses were undertaken using a Bruker Advance II spectrometer (Wissembourg, France) ( $400 \mathrm{MHz}$ ) equipped with a $4 \mathrm{~mm}$ diameter rotor ${ }^{1} \mathrm{H}^{-13} \mathrm{C}$ HR-MAS probe with z-gradient coil at $5 \mathrm{kHz}$ rotation speed operating at $298 \mathrm{~K}$.

Thermogravimetric analyses (TGA) of all the epoxy-IL and their hybrid O/I networks and were performed using a Q500 thermogravimetric analyzer (TA Co. Ltd., New Castle, DE, USA). The samples were heated from 30 to $900{ }^{\circ} \mathrm{C}$ at a heating rate of $20 \mathrm{~K} \cdot \mathrm{min}^{-1}$ under nitrogen and air flow.

Differential scanning calorimetry analyses (DSC) of ILMs reactive system and thermosetting networks were performed on a Q10 (TA Co. Ltd., New Castle, DE, USA) in a dynamic mode, i.e., with a heating rate of $10 \mathrm{~K} \cdot \mathrm{min}^{-1}$ under nitrogen flow of $50 \mathrm{~mL} \cdot \mathrm{min}^{-1}$ from -70 to $300{ }^{\circ} \mathrm{C}$.

The morphology of the networks was evaluated by transmission electron microscopy (Philips CM120) (Waltham, MA, USA). Samples $60 \mathrm{~nm}$ thick were previously cut by ultramicrotomy and placed on a copper grid for analysis. 
Surface energy of epoxy networks was determined according to the sessile drop method using a GBX goniometer (Dublin, Ireland). From contact angle measurements performed with water and methylene diiodide as probe liquids, nondispersive and dispersive components of surface energy were determined according to the Owens-Wendt theory [48].

Dielectric spectroscopy measurements were performed on an Ametek Solartron XM spectrometer (Elancourt, France). The measuring cell and cooling system were supplied by Janis Research Company. A sinusoidal voltage of $\pm 5 \mathrm{~V}$ is applied to the terminals of the sample, for a frequency range defined from $10^{6}$ to $10^{-1} \mathrm{~Hz}$. Two temperature sweeps from -80 to $200{ }^{\circ} \mathrm{C}$ were applied successively, with an isothermal measurement in frequency sweep every $3{ }^{\circ} \mathrm{C}$. The electrodes used are made of brass and have a diameter of $25 \mathrm{~mm}$. In order to ensure electrical contact, the samples are first metallized with gold. Dielectric measurements were undertaken under isothermal conditions (3K temperature steps) with a frequency range from $1 \mathrm{MHz}$ to $0.1 \mathrm{~Hz}$ (10 points per decade) applying $\mathrm{V}_{\mathrm{rms}}=5 \mathrm{~V}$. The complex conductivity, $\sigma^{*}$, was calculated from the Equation (1):

$$
\sigma^{*}(\omega)=\omega \cdot \varepsilon_{0} \cdot \varepsilon^{*}(\omega)
$$

where the angular frequency $\omega=2 \pi \mathrm{f}$ ( $\mathrm{f}$ being the frequency), $\varepsilon_{0}$ the vacuum permittivity $\left(8.85 \times 10^{-12} \mathrm{~F}^{-1} \mathrm{~m}^{-1}\right)$, and $\varepsilon^{*}$ the complex permittivity of the material. The DC conductivity measurements were carried out at low temperature $\left(T<\mathrm{T}_{\mathrm{g}}\right)$. The $\sigma_{\mathrm{DC}}$, was extrapolated from the real part of the conductivity $\sigma^{\prime}(\omega)=\omega \cdot \varepsilon_{0} \cdot \varepsilon^{\prime \prime}(\omega)$ for $\omega \rightarrow 0$, where a plateau is observed.

\section{Results and Discussion}

\subsection{Morphology of Hybrid O/I Networks}

Considering phenyltrisilanol POSS ${ }^{\circledR}\left(\mathrm{POSS}^{\circledR P h}\right.$-triol) or IL-g-POSS ${ }^{\circledR P h}$ combined with the various counter anions, i.e., chloride $\left(\mathrm{Cl}^{-}\right)$versus bistriflimide $\left(\mathrm{NTf}_{2}{ }^{-}\right)$, homogeneous and transparent mixtures with DGEBA or ILMs and IPD have been observed. This phenomenon confirms the solubility of all the monomers at the initial stage, i.e., before polymerization. The miscibility could be associated with the formation of intermolecular interactions (e.g., including Van der Waals, electrostatic, solvophobic, steric, and hydrogen bonds interactions) between POSS ${ }^{\circledR P h}$ and ILMs or DGEBA (and/or IPD). These homogeneous and transparent mixtures based on $5 \mathrm{wt} . \%$ of non-modified (POSS ${ }^{\circledR P h}$-triol) or IL-modified POSS ${ }^{\circledR P h}$ (IL-g-POSS ${ }^{\circledR P h}$ ) were cured at elevated temperatures to prepare in situ hybrid organic-inorganic networks. It was observed during the curing reaction that for DGEBA prepolymer-based systems, the initially transparent solutions gradually became cloudy evidencing the occurrence of a phase separation. This phenomenon is induced by polymerization and is denoted RIPS (Reaction Induced Phase Separation). However, with ILMs, the resulting networks were homogeneous and transparent; i.e., no discernible phase separation occurred at micro/macroscale.

Transmission electron microscopy was considered to highlight the dispersion state of the POSS ${ }^{\circledR P h}$-triol and IL-g-POSS ${ }^{\circledR P h}$ nanoclusters into epoxy networks as well as the formation of a possible interphase between the epoxy ILM-based network and POSS ${ }^{\circledR P h}$ POSS ${ }^{\circledR P h}$ aggregates. The morphologies obtained of the epoxy hybrid O/I networks are displayed in Figure 1. In all TEM micrographs, the dark part corresponds to the POSS ${ }^{\circledR P h}$ rich phases whereas the brightest continuous phase corresponds to the epoxy ILM/IPD matrix. 

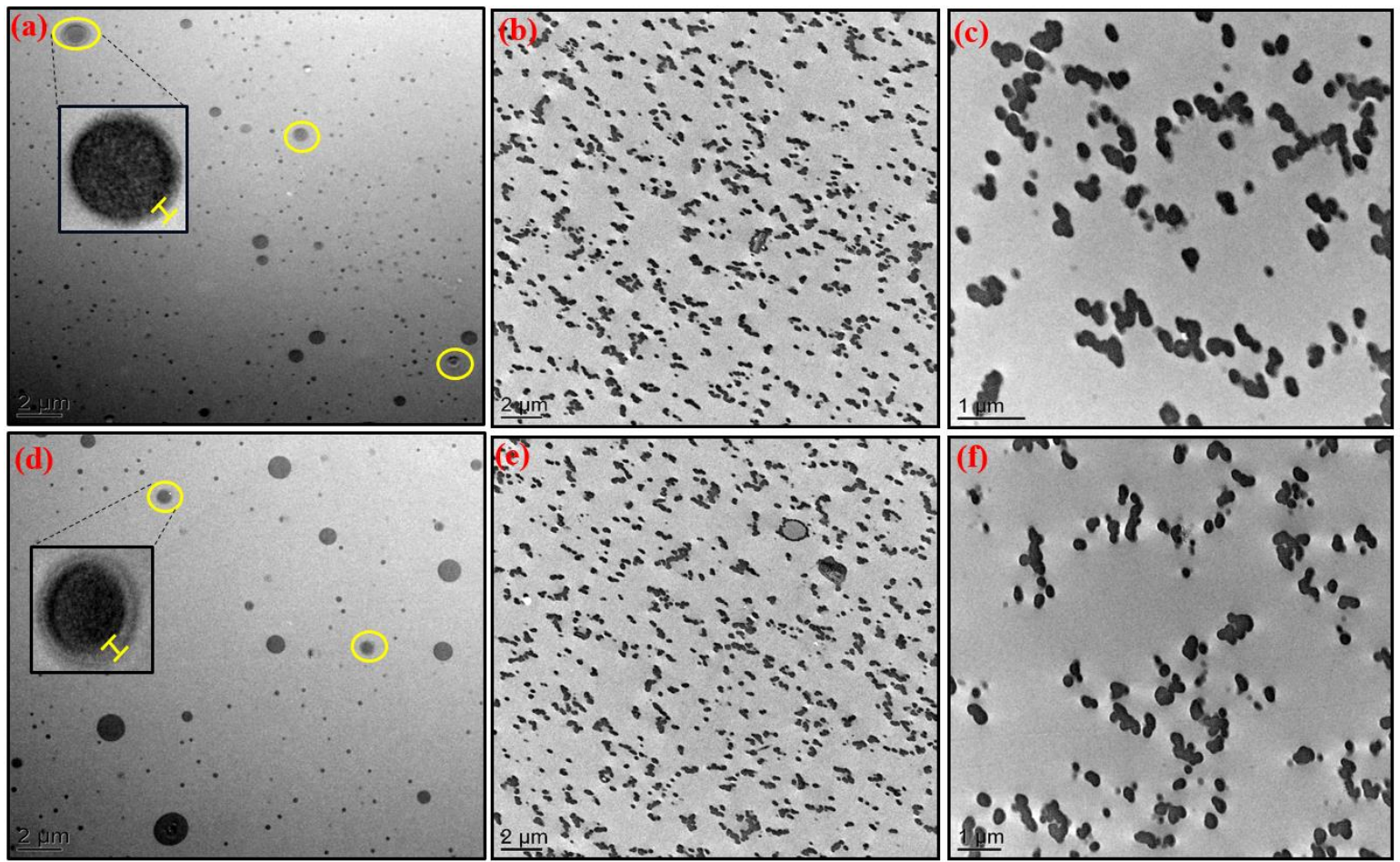

Figure 1. TEM images of the different epoxy ILM hybrid O/I networks containing POSS ${ }^{\circledR P h}$-triol, IL.Cl-g-POSS ${ }^{\circledR P h}$ and IL.NTf I-g-POSS $^{\circledR P h}$, respectively, prepared with epoxy monomer ILM1 (a-c), and with ILM2 (d-f).

In all cases, i.e., the epoxy networks based on ILM1 or ILM2 containing POSS ${ }^{\circledR P h}$-triol or IL-g-POSS ${ }^{\circledR P h}$, a homogeneous distribution of nanoclusters aggregates in the epoxy matrix was revealed by TEM. The main difference between the epoxy ILM/POSS ${ }^{\circledR P h}$-triol and ILM/IL-g-POSS ${ }^{\circledR P h}$ (Figure 1) hybrid networks is the average size of the POSS ${ }^{\circledR P h}-$ POSS $^{\circledR P h}$ aggregates. The POSS ${ }^{\circledR P h}$-rich dispersed phases have a spherical or ellipsoidal shape in the different systems, with a diameter range from 60 to $900 \mathrm{~nm}$ for the epoxy networks based on ILM1 or ILM2 epoxy monomers. Such features are usually encountered for conventional morphologies generated from a phase separation induced during polymerization [49-51]. In both epoxy networks (ILM1 or ILM2-based ones) containing POSS ${ }^{\circledR P h}$-triol, the formation of an interface is observed around some POSS ${ }^{\circledR P h}$ aggregates as shown in Figure 1a,d. This interface has an average thickness included between 10 and $30 \mathrm{~nm}$ measured directly from the TEM images by using Image J Software (ImageJ bundled with 64-bit Java 1.8.0_172, 2020). This interface represented about $2 \%$ of the total volume of the POSS aggregate. This interface can be also explained by the low amount of POSS ${ }^{\circledR P h}$-triol nanoclusters which reacted with the epoxy-amine matrix. The interconnected nanophase-separated morphology with uniform domain size is characteristic of self-assembled structures generated as result of a balance of different intermolecular and intercluster interactions [52,53]. It should be pointed out that the dispersion of POSS ${ }^{\circledR P h}$-triol clusters in the ILM1 or ILM2-based matrix is better than the one obtained with DGEBA/IPD network, where the diameter distribution is ranging from 0.1 to $1.5 \mu \mathrm{m}$ [45]. For epoxy ILM/IPD networks containing IL-g-POSS ${ }^{\circledR P h}$ with chloride $\left(\mathrm{Cl}^{-}\right)$or bistrifluoromethanesulfonimidate $\left(\mathrm{NTf}_{2}{ }^{-}\right)$counter anions, the TEM micrographs show that the phase separation occurred at nanoscale. In fact, the POSS ${ }^{\circledR}$-rich dispersed phase shows spherical shapes based on small assemblies of POSS ${ }^{\circledR P h}$, with an average diameter from 80 to $400 \mathrm{~nm}$ (Figure 1), which can be seen as the result of the nanostructuration of POSS ${ }^{\circledR P h}$ cages. In addition, the dispersion of IL-g-POSS ${ }^{\circledR P h}$ having a $\mathrm{Cl}^{-}$anion in the ILM1 or ILM2 epoxy monomer-based networks is always better than the one for IL-g-POSS ${ }^{\circledR P h}$ having a $\mathrm{NTf}_{2}{ }^{-}$anion (uniform state of dispersion and aggregates sizes). These differences can be explained by the higher nucleophilicity and the smaller 
molar mass of the chloride anion compared to the $\mathrm{NTf}_{2}{ }^{-}$anion [54]. The $\mathrm{Cl}^{-}$provides a higher mobility leading to a high reactivity with the ILMs monomers. According to the literature, various authors have explored the ability of imidazolium ionic liquid to be used as a dispersing agent or dispersion media [55]. In fact, these ones could facilitate the dispersion of metallic [56] or inorganic particles [57] as well as carbon nanotubes [58]. The average size and size distribution of nanoparticles are managed from the physico-chemical properties of ionic liquids. For example, stabilization of bare silica nanoparticles by imidazolium-based ionic liquids was found to be tuned by the affinity between the ions and particle surface according to careful selection of the ions of ILs and/or the nanoparticle surface modification. Such a management could optimize the ionic liquid-based steric stabilization provided by the non-polar alkyl chains as a protecting group [59]. Donato et al. have obtained welldispersed silica aggregates (of about $30 \mathrm{~nm}$ ) for $6.8 \mathrm{wt}$.\% of IL-functionalized silica particles having different counter anions $\left(\mathrm{Cl}^{-}\right.$and $\left.\mathrm{MeSO}_{3}{ }^{-}\right)[60,61]$. These obtained dispersions are finer than those using a metal complex catalyst, i.e., aluminum triacetylacetonate ([Al]) which is used to reduce the size of POSS ${ }^{\circledR P h}$-triol aggregation [32] or by substitution of DGEBA with TGDDM epoxy prepolymer [31]. As conclusion, the use of imidazolium ILMs as new monomers could be a promising route to achieve a nanoscale filler structuration in thermoset (epoxy) networks and to design nanomaterials combining properties from both ionic liquid and nanoclusters. Such nanomaterials could be useful as novel hybrid materials for electrochemistry applications.

\subsection{Epoxy Conversion and Glass Transition Temperatures}

It has been noticed that the presence of POSS ${ }^{\circledR}$ cages on glass transition temperature of the hybrids is dependent on the nature of corner $\mathrm{R}$ groups on silsesquioxane cages and an epoxy matrix. The DSC thermograms of $\mathrm{POSS}^{\circledR P h}$-based hybrid O/I networks display a single glass transition temperature, i.e., the hybrid materials are homogenous [50]. The glass transition of the neat epoxy ILM/IPD networks occurred at 71 and at $54{ }^{\circ} \mathrm{C}$ for ILM1/IPD and ILM2/IPD networks, respectively (Figure S1). It can be noticed that all the hybrids O/I containing POSS ${ }^{\circledR P h}$-triol or IL-g-POSS ${ }^{\circledR P h}$ (whatever the chemical nature of the anion, chloride, or bis-triflimide- $\left.\mathrm{NTf}_{2}{ }^{-}{ }^{-}\right)$show a decrease of their glass transition temperature (60 and $45^{\circ} \mathrm{C}$ for ILM1/IPD and ILM2/IPD networks, respectively) (Figure 2a,b). Nevertheless, the ILM2/IPD epoxy network containing POSS ${ }^{\circledR P h}$-triol displays higher $\mathrm{T}_{\mathrm{g}}$ $\left(74^{\circ} \mathrm{C}\right)$ compared to the neat epoxy ILM2/IPD and the O/I hybrid containing IL-g-POSS ${ }^{\circledR P h}$ networks (Figure $2 \mathrm{~b}$ ).

It can be proposed that the decrease of the glass transition temperature results from the incomplete curing reaction of the ILMs monomers due to the presence of POSS ${ }^{\circledR P h}$ nanoclusters [62]. To confirm such an assumption, the epoxy conversion was determined by FTIR and the ${ }^{13}$ C HR-MAS NMR. As shown in Figures S2 and S3 (see Supplementary Materials), a high conversion of epoxy-groups was obtained (>90\%) and the total disappearance of the epoxy peaks (at 34, 47, and 52 ppm in the ${ }^{13} \mathrm{C}-\mathrm{NMR}$ spectra) after the curing procedure confirmed that the curing reactions are completed $[46,47]$. Therefore, the decrease of the glass transition temperatures cannot be associated to a non-fully completed curing reaction resulting from the incorporation of POSS ${ }^{\circledR P h}$-triol or IL-g-POSS ${ }^{\circledR P h}$ nanoclusters.

According to the literature, it has been reported for octa-aminophenyl POSS ${ }^{\circledR}$ and octa-nitrophenyl POSS ${ }^{\circledR}$-modified epoxies [50] that with a low content of POSS ${ }^{\circledR P h}$, a $\mathrm{T}_{\mathrm{g}}$ decrease is observed. This decrease can be ascribed to the increase of free volume of the system due to the insertion of bulky POSS ${ }^{\circledR P h}$ cages between chains. According to the literature, two competitive factors can influence the glass transition temperatures. First, the steric hindrance effect of POSS $^{\circledR}$ cages on polymer chain motions will contribute to increase the glass transition temperature via reduction of local chain motions. Secondly, the inclusion of bulky POSS $^{\circledR}$ cages could give rise to the increase of free volume leading to a decrease of the $T_{g}$. Nevertheless, the $T_{g}$ depends on the nature of the interactions between POSS $^{\circledR}$ cages and polymer chains which are controlled by surrounding groups of the POSS ${ }^{\circledR}$ cage, the nature of polymer matrix, and organic groups in POSS ${ }^{\circledR}$ vertexes, etc. Thus, POSS ${ }^{\circledR}$ 
could act on segmental motions of polymer chains as a nanofiller (surface interactions reducing mobility) or a plasticizer (increase in free volume). In fact, POSS ${ }^{\circledR P h}$-containing nanomaterials can display increased $[50,63,64]$ or decreased $[65,66] \mathrm{T}_{\mathrm{g}}$ compared to neat polymers. The introduction of POSS ${ }^{\circledR P h}$-triol or IL-g-POSS ${ }^{\circledR P h}$ in ILM1/IPD or ILM2/IPD networks led to an increase of free volume. The increased $\mathrm{T}_{\mathrm{g}}$ for the $\mathrm{O} / \mathrm{I}$ hybrid network containing POSS ${ }^{\circledR P h}$-triol based on ILM2/IPD matrix could be associated to the reactions between POSS ${ }^{\circledR P h}$-triol and epoxy groups.

Then, a decrease of the $T_{g}$ could be attributed to: $i /$ possible secondary reactions between IL-g-POSS ${ }^{\circledR P h}$ and epoxy ILM monomers generated by the anion $\left(\mathrm{Cl}^{-}\right.$or $\left.\mathrm{NTf}_{2}{ }^{-}\right)$[54], or iii/secondary reactions between the hydroxyl silanol of the POSS ${ }^{\circledR P h}$ cages and the epoxy groups [63]. To confirm these assumptions, the remaining soluble fractions after curing schedule of the different systems were determined. In the case of epoxy ILM/IPD networks containing POSS ${ }^{\circledR P h}$-triol, the soluble fraction was determined to be $4.2 \%$ with ILM1/IPD and 4.0\% with ILM2/IPD which means that some POSS ${ }^{\circledR P h}$-triol clusters (about 16 to $20 \%$ ) are chemically attached to the epoxy networks. For the IL grafted-POSS ${ }^{\circledR P h}$, the soluble fraction was found for both epoxy ILM/IPD networks to be about 3.8 and 3.6\% for IL.Cl-g-POSS ${ }^{\circledR P h}$ and for IL.NTf 2 -g-POSS ${ }^{\circledR P h}$, respectively. In addition, a covalent grafting of these IL-modified POSS ${ }^{\circledR P h}$ with the epoxy networks is ensured for about 24 to $28 \%$ of the nanoclusters, while the rest of POSS ${ }^{\circledR P h}$ remain non-bounded to the epoxy network. In summary, the incorporation of IL.Cl-g-POSS ${ }^{\circledR P h}$ and IL.NTf ${ }_{2}-$ g-POSS ${ }^{\circledR P h}$ led to an increase of the free volume reducing the $\mathrm{T}_{\mathrm{g}}$ of the networks.
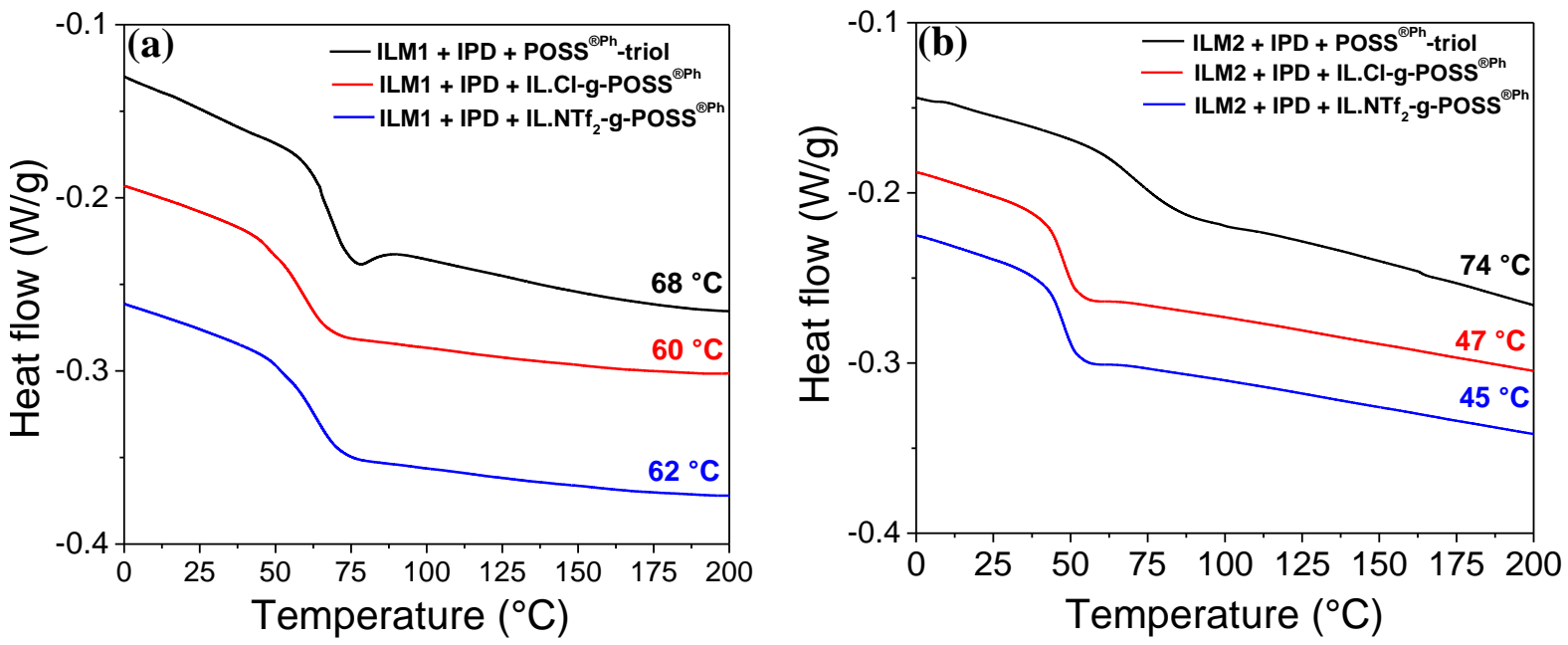

Figure 2. DSC traces of the epoxy hybrid O/I networks based on epoxy IL monomers (a) ILM1, and (b) ILM2-containing POSS ${ }^{\circledR P h}$-triol, IL.Cl-g-POSS ${ }^{\circledR P h}$, and IL.NTf 2 -g-POSS ${ }^{\circledR P h}$, respectively.

\subsection{Thermal Stability and Oxidative Resistance of Hybrid O/I Networks}

Epoxies usually display a low flame retardancy. In addition, to obtain a higher thermostability of such polymer materials, multicomponent fire retardants are used, such as compounds containing $\mathrm{Si}, \mathrm{N}, \mathrm{P}$, and halogens $[67,68]$. As described in our previous works [59], POSS ${ }^{\circledR P h}$ cages allow the generation of a ceramic-like surface layer during combustion which protects the inside matrix from oxidation limiting oxygen availability. In fact, such an inorganic surface barrier could limit the attack from the oxygen radical and the active radicals issued from degraded species, i.e., contributing to improve the resistance to oxidation. Moreover, the $\mathrm{Cl}^{-}$and $\mathrm{NTf}_{2}{ }^{-}$anions introduced via the ionic liquids can quench the active radical and limit the probability of chain reaction [69]. For such a behavior, the effects of IL-functionalized POSS ${ }^{\circledR}$ on the thermal stability of networks based on ILM monomers have been investigated.

Thermal stability and thermo-oxidative resistance of the epoxy hybrid O/I networks were investigated from thermogravimetric analyses (TGA) under air (to favor oxidation 
reactions) and inert atmosphere (intrinsic degradation). According to such protocols, the influence of POSS ${ }^{\circledR P h}$-triol and IL-g-POSS ${ }^{\circledR P h}$ nanoclusters on the pyrolysis-oxidation resistance of the epoxy ILM/IPD networks was examined. This evaluation was undertaken from the weight change under air atmosphere as a function of the temperature, the initial decomposition temperature $\left(\mathrm{T}_{\mathrm{d} 5 \%}\right)$, and the maximal degradation temperature $\left(\mathrm{T}_{\mathrm{dmax}}\right)$ (Figure $3 a, b$ as well as Figure S4a,b under inert atmosphere).
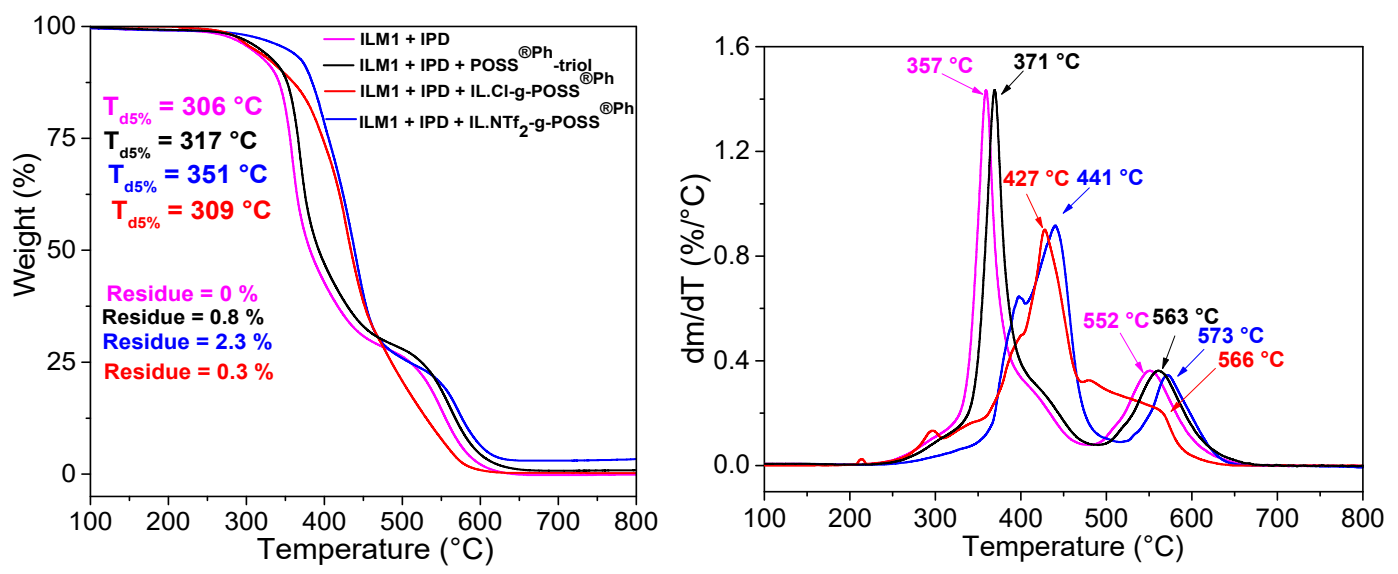

(a)
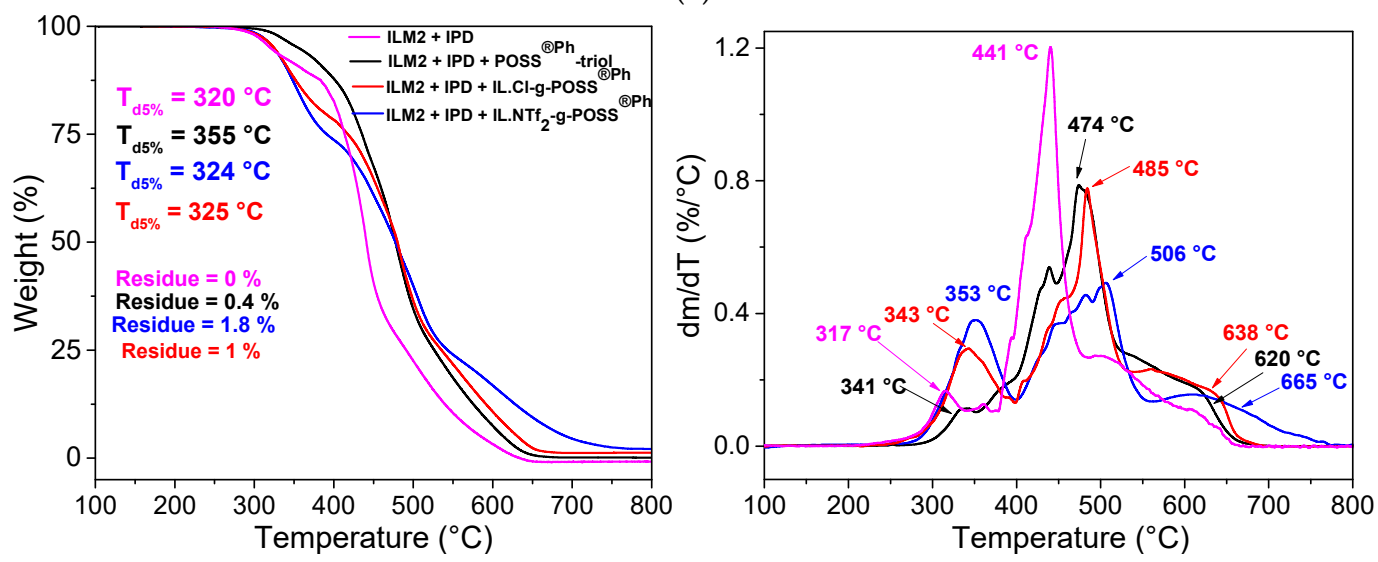

(b)

Figure 3. Evolution of weight loss (TGA) and derivative of TGA curves (DTG) as a function of the temperature for the epoxy hybrid O/I networks (prepared based on epoxy monomers: (a) ILM1, and (b) ILM2) containing POSS ${ }^{\circledR P h}$-triol, IL.Cl-g-POSS ${ }^{\circledR P h}$, and IL.NTf -g-POSS $^{\circledR P h}$, respectively.

The thermal degradation (Figure S4a,b in the Supplementary Materials) proceeds from two decomposition steps for the different epoxy hybrid $\mathrm{O} / \mathrm{I}$ networks under nitrogen atmosphere. These steps occur between $250-400{ }^{\circ} \mathrm{C}$ and $400-550{ }^{\circ} \mathrm{C}$ defined from the vertex group degradation and dehydration-vaporization mechanism [70] at higher temperature $\left(900{ }^{\circ} \mathrm{C}\right.$ ) producing a stable black residue (6 to $18 \mathrm{wt}$ \%). Under air, a similar behavior is obtained. The $\mathrm{O} / \mathrm{I}$ hybrid epoxy networks display the same decomposition profiles with a low degradation temperature $\left(\mathrm{T}_{\mathrm{d} 5 \%}\right)$ similar to other POSS ${ }^{\circledR}$-modified systems [71]. The thermograms also show a third decomposition step at higher temperature (from 550 to $750{ }^{\circ} \mathrm{C}$ ) related to the maximum rate of vaporization and completed oxidation combustion reactions (Figure $3 a, b$ ) leading to almost no residue (from 0.3 to $2.3 \%$ ). Residue production yield decreases for all $\mathrm{O} / \mathrm{I}$ hybrid epoxy networks under air atmosphere compared to the ones obtained under nitrogen atmosphere. The ILM/IPD networks based on IL.NTf I-g- $^{-}$ POSS $^{\circledR P h}$ lead to more residue than the networks containing IL.Cl-g-POSS ${ }^{\circledR P h}$ or POSS ${ }^{\circledR P h}$ triol. The difference on the residue content could be explained by the competition between 
the sublimation and/or vaporization and the full oxidation reactions at high temperature in relation to the POSS ${ }^{\circledR P h}$ content, which are grafted to the epoxy networks. Thermal stability, degradation kinetics, and residue content of the $\mathrm{O} / \mathrm{I}$ hybrid epoxy networks depend mainly on the nature of the organic groups surrounding the POSS ${ }^{\circledR P h}$ inorganic cage but also that to the chemical nature of the co-monomers considered to build the epoxy networks (ILM1 or ILM2).

As can be seen in Figure 3a,b the epoxy hybrid O/I networks containing POSS ${ }^{\circledR P h}$-triol or IL-g-POSS ${ }^{\circledR P h}$ nanoclusters with chloride or bistriflimide $\left(\mathrm{NTf}_{2}{ }^{-}\right)$as counter anions have a higher thermal stability $\left(\mathrm{T}_{\mathrm{d} 5 \%}, \mathrm{~T}_{\mathrm{dmax}}\right)$ and a higher oxidation resistance than the neat epoxy networks (ILM1 or ILM2/IPD). Such behavior could be associated to the nanoscale dispersion of POSS ${ }^{\circledR P h}$-triol or IL-g-POSS ${ }^{\circledR P h}$ clusters in the epoxy matrices as well as to the improved interactions between the ILM monomers and POSS ${ }^{\circledR P h}$-POSS ${ }^{\circledR P h}$ aggregates. In addition, the increased $\mathrm{T}_{\mathrm{d}}$ for epoxy hybrids containing POSS ${ }^{\circledR P h}$ could result from the increased chain spacing which modify also the thermal conductivity of POSS ${ }^{\circledR P h}$-modified networks. The POSS ${ }^{\circledR}$ ceramization is another important effect which could contribute to improving the thermostability. In general, POSS ${ }^{\circledR}$ cage as a ceramic [72] precursor forms silica layer after completed oxidation. After the emission of organic groups in $\mathrm{POSS}^{\circledR P h}$ cages, the silica layer seals the polymer, retards the oxidation of bulk polymer. On the other hand, $\mathrm{POSS}^{\circledR}$ is a surface-active moiety, tending to migrate to the surface as a tenside [73]. It is worth of underlining that the $\mathrm{O} / \mathrm{I}$ hybrid epoxy networks based on ILM2 exhibit the highest thermal stability $\left(\mathrm{T}_{\mathrm{d} 5 \%}\right)$ and resistance towards oxidation (DTG peak concerning the network contained IL.NTf 2 -g-POSS ${ }^{\circledR P h}, 665^{\circ} \mathrm{C}$ with ILM2/IPD against $573{ }^{\circ} \mathrm{C}$ with ILM1/IPD matrix) compared to the epoxy hybrid O/I networks based on ILM1.

\subsection{Surface Properties of Hybrid O/I Networks}

Total surface energies of the epoxy hybrid O/I networks containing POSS ${ }^{\circledR P h}$-triol, IL.Cl-g-POSS ${ }^{\circledR P h}$, and IL.NTf ${ }_{2}$-g-POSS ${ }^{\circledR P h}$ prepared from co-polymerization of ILM1 or ILM2 with IPD monomers are summarized in Table 2.

Table 2. Determination of dispersive and non-dispersive components of the surface energy on the neat epoxy DGEBA/IPD, ILM/IPD and the corresponding hybrid O/I networks from contact angle with water and methylene diiodide at room temperature.

\begin{tabular}{|c|c|c|c|c|c|}
\hline Samples & $\underset{\left({ }^{\circ}\right)}{\Theta_{\text {Water }}}$ & $\underset{\left.{ }^{(}\right)}{\Theta_{(\mathrm{CH} 2 \mathrm{I} 2}}$ & $\begin{array}{c}\gamma_{\text {non-dispersive }} \\
\left(\mathrm{mJ} \cdot \mathrm{m}^{-2}\right)\end{array}$ & $\begin{array}{l}\gamma_{\text {dispersive }} \\
\left(\mathrm{mJ}^{\left.-\mathrm{m}^{-2}\right)}\right.\end{array}$ & $\begin{array}{c}\gamma_{\text {total }} \\
\left(\mathrm{mJ} . \mathrm{m}^{-2}\right)\end{array}$ \\
\hline DGEBA/IPD & 79 & 49 & 4.8 & 34.8 & 39.6 \\
\hline ILM1/IPD & 102 & 62 & 0.8 & 24.6 & 25.4 \\
\hline ILM1-IPD/POSS ${ }^{\circledR P h}$-triol & 108 & 75 & 0.3 & 20.4 & 20.7 \\
\hline ILM1-IPD/IL.Cl-g-POSS ${ }^{\circledR P h}$ & 110 & 78 & 0.3 & 19.9 & 20.2 \\
\hline ILM1-IPD/IL.NTf ${ }_{2}-\mathrm{g}-\mathrm{POSS}{ }^{\circledR P h}$ & 112 & 82 & 0.2 & 19.6 & 19.8 \\
\hline ILM2/IPD & 106 & 72 & 0.6 & 21.0 & 21.6 \\
\hline ILM2-IPD/POSS ${ }^{\circledR P h}$-triol & 115 & 86 & 0.2 & 19.4 & 19.6 \\
\hline ILM2-IPD/IL.Cl-g-POSS ${ }^{\circledR P h}$ & 116 & 88 & 0.2 & 18.8 & 19.0 \\
\hline ILM2-IPD/IL.NTf ${ }_{2}$-g-POSS ${ }^{\circledR P h}$ & 120 & 92 & 0.2 & 18.0 & 18.2 \\
\hline
\end{tabular}

First, the results revealed that the substitution of DGEBA with the ILMs and the introduction of $5 \mathrm{wt}$.\% of POSS ${ }^{\circledR P h}$-triol or IL-g-POSS ${ }^{\circledR P h}$ (with $\mathrm{Cl}^{-}$or $\mathrm{NTf}_{2}{ }^{-}$anion) considerably increased the contact angles formed by the probe liquids at the surface of the epoxy networks (ILM/IPD). Taking into account the increase of the contact angles of these two probe liquids on ILM/IPD/POSS ${ }^{\circledR P h}$ surfaces, one can conclude that the introduction of the POSS ${ }^{\circledR P h}$ and the substitution of DGEBA by ILM monomers increase the hydrophobic and oleophobic characteristics of the surface. In addition, it is interesting to observe that the values obtained are similar to ones measured for different fluorinated polymers such as PTFE, i.e., $110-120^{\circ}$ for water and $82-83^{\circ}$ for methylene diiodide $[74,75]$ confirming the hydrophobic character of the epoxy network surfaces. 
A more detailed analysis taking into account the polar components and dispersive of the surface energy of the epoxy hybrid O/I networks shows that the dispersive component is the major contribution of the surface energy (98\%). Consequently, the interactions initiated by this type of surface are mainly London dispersive interactions. As DGEBA monomer is replaced by ILMs and modified by the incorporation of the POSS ${ }^{\circledR P h}$ nanoclusters, a significant decrease of the dispersive component is observed (from $35 \mathrm{~mJ} . \mathrm{m}^{-2}$ for DGEBA/IPD (see Table 2) to $18 \mathrm{~mJ} \cdot \mathrm{m}^{-2}$ for ILM2/IPD/IL.NTf ${ }_{2}$-g-POSS ${ }^{\circledR P h}$ ). At the same time, the non-dispersive component of the initially low surface energy is also decreased. The London dispersive interactions are still predominant but are reduced by the addition of the POSS ${ }^{\circledR P h}$ leading to a decrease of the total surface energy. These results can be explained by the hydrophobic contribution brought by the POSS ${ }^{\circledR P h}$ molecules having phenyl ligands [76] and epoxy ionic liquids monomers containing imidazolium units with $\mathrm{NTf}_{2}{ }^{-}$anions $[77,78]$. These units are well-known to lower surface tension [79]. In addition, the ILM/IPD networks containing POSS ${ }^{\circledR P h}$-triol or IL-g-POSS ${ }^{\circledR P h}$ networks display a more pronounced hydrophobic character than one of the DGEBA/IPD modified by POSS ${ }^{\circledR P h}$ network. These new results combined with the high thermal stability open new and promising routes in the preparation of surface coatings with self-cleaning and anti-corrosion properties for automotive, aerospace, or electronics applications.

\subsection{Ionic Conductivity of Hybrid O/I Networks}

In order to characterize the ILM/IPD epoxy networks and the corresponding hybrid networks for potential solid polymer electrolytes applications, dielectric measurements under AC voltage were carried out. Thus, the influence of IL-g-POSS ${ }^{\circledR P h}$ nanoclusters could be analyzed. The real, $\varepsilon^{\prime}$, and the imaginary, $\varepsilon^{\prime \prime}{ }_{r}$, parts of the complex relative permittivity were extracted from measurements undertaken under $5 \mathrm{~V}$ sinusoidal applied voltage (Figure $4 a, b)$. In order to evaluate the DC conductivity (quasi-steady state) at high temperatures, it is required to start by evaluating the changes taking place in the AC conductivity domain. Figure 5 gives the changes of AC conductivity as function of frequency for the epoxy DGEBA and ILM1 or ILM2 cured with IPD as well as the different hybrid O/I networks obtained from the addition of IL-g-POSS ${ }^{\circledR P h}$ with the two different anions: chloride $\left(\mathrm{Cl}^{-}\right)$or bis-trifluoromethanesulfonimidate $\left(\mathrm{NTf}_{2}{ }^{-}\right)$. Taking into account the fact that the glass transition temperatures of the ILM/IPD networks and their corresponding $\mathrm{O} / \mathrm{I}$ hybrid networks, which vary from 45 to $71^{\circ} \mathrm{C}$ (see Figure 3 and Figure $\mathrm{S} 1$ ), the conductivity was measured from -80 up to $200{ }^{\circ} \mathrm{C}$ for the DGEBA/IPD and up to $150{ }^{\circ} \mathrm{C}$ for ILM/IPD (the same for their hybrid O/I networks).
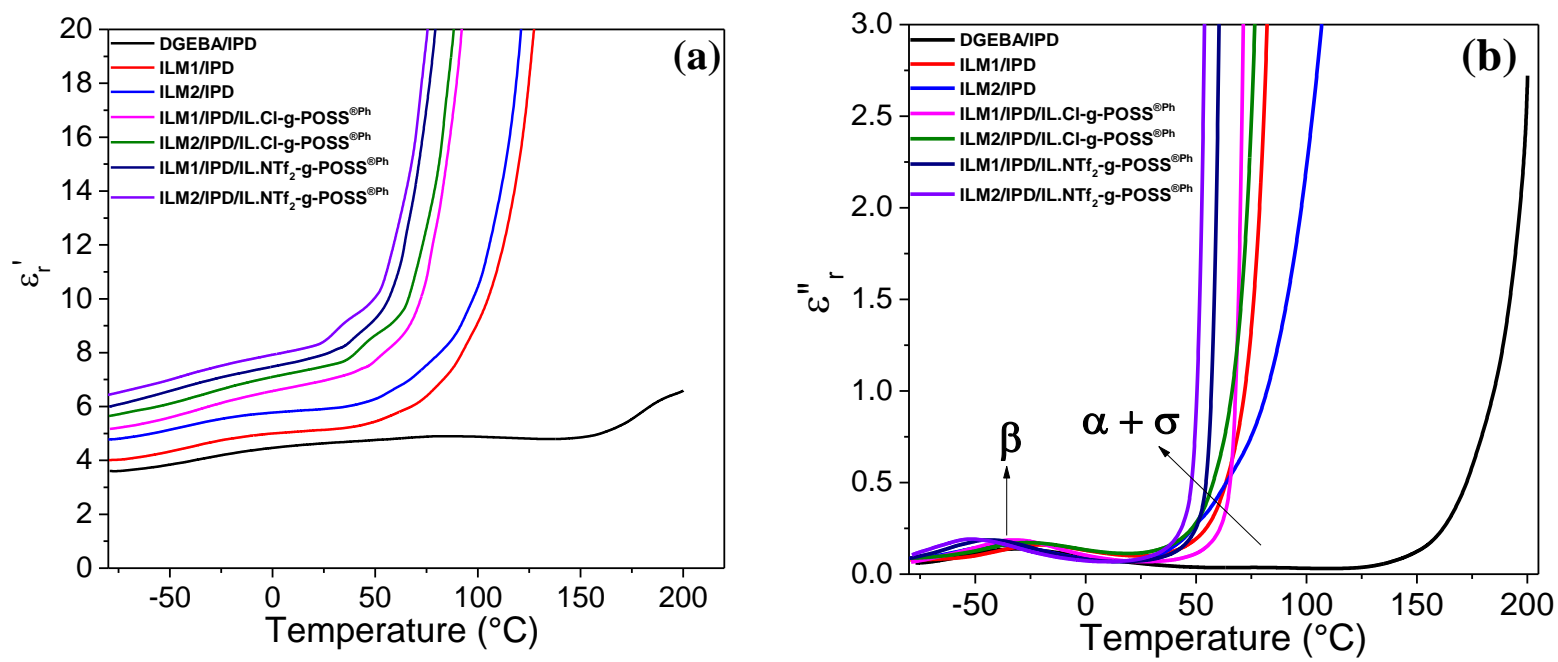

Figure 4. Evolution of relative real permittivity (a), and imaginary part (b) as a function of temperature at $100 \mathrm{~Hz}$ of DGEBA/IPD network, ILM/IPD network, and the corresponding hybrid O/I epoxy networks. 
(a) DGEBA/IPD

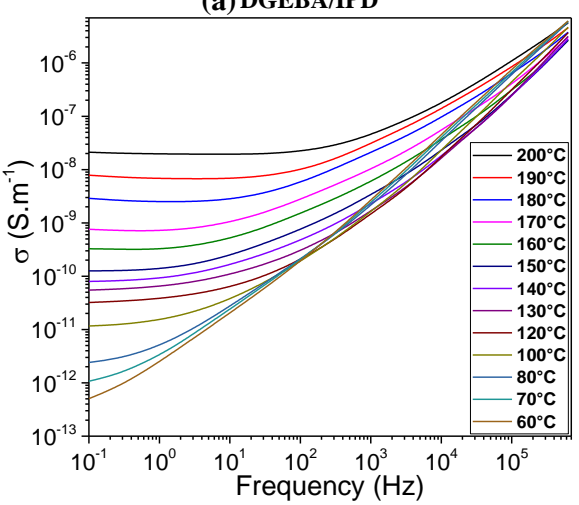

(c) ILM2/IPD

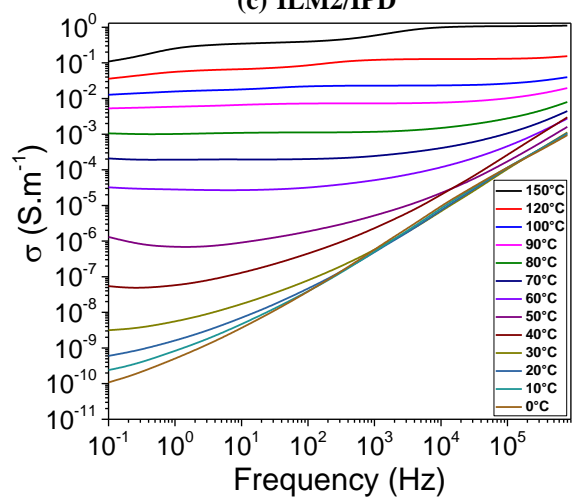

(e) ILM2/IPD/IL.Cl-g-POSS ${ }^{\mathrm{Ph}}$

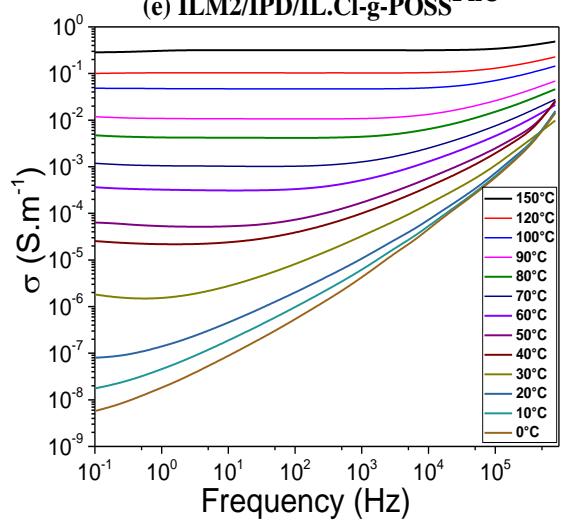

(b) ILM1/IPD

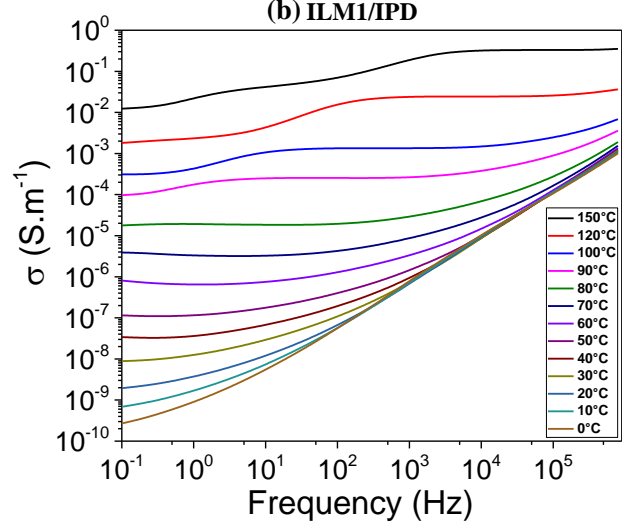

(d) ILM1/IPD/IL.Cl-g-POSS ${ }^{\mathrm{Ph} ®}$

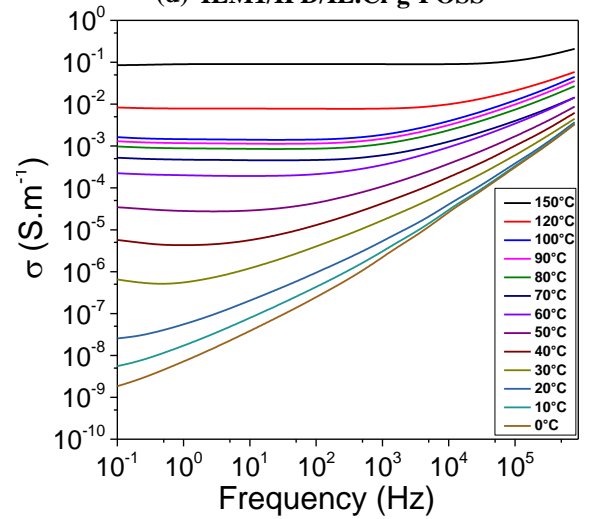

(f) ILM1/IPD/IL.NTf IL-POSS $^{\mathrm{Ph} \circledast}$

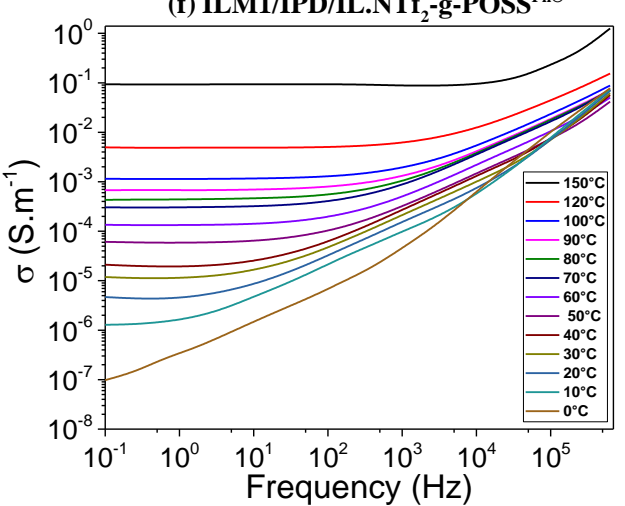

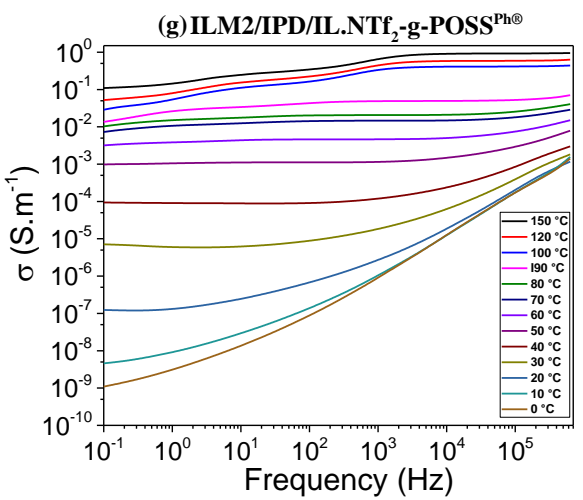

Figure 5. Evolution of $\mathrm{AC}$ conductivity as a function of frequency for (a) DGEBA/IPD, (b) ILM1/IPD, (c) ILM2/IPD, (d) ILM1/IPD/IL.Cl-g-POSS ${ }^{\circledR P h}$, (e) ILM2/IPD/IL.Cl-g-POSS ${ }^{\circledR P h}$, (f) ILM1/IPD/IL.NTf 2 -g-POSS ${ }^{\circledR P h}$, and (g) ILM2/IPD/IL.NTf 2 -g-POSS ${ }^{\circledR P h}$. 
The neat epoxy network (DGEBA/IPD) shows relative permittivity, $\varepsilon^{\prime}{ }_{\mathrm{r}}$, starting from 3.5 at low temperature and up to 6 at temperatures higher than room temperature. A slight increase with a maximum value close to $170{ }^{\circ} \mathrm{C}$ corresponds to the $\alpha$ relaxation of the epoxy system. The ILM/IPD and their corresponding O/I hybrids obtained by the introduction of $5 \mathrm{wt} . \%$ of IL-g-POSS ${ }^{\circledR P h}$ nanoclusters with the chloride or bistriflimide $\left(\mathrm{NTf}_{2}{ }^{-}\right)$anions have relative permittivity, $\varepsilon^{\prime}$, much higher (from 30 to 50\%) at room temperature and also show an exponential increase after the glass transition temperature (between 50 and $80^{\circ} \mathrm{C}$ depending on the epoxy system) to achieve high values at higher temperatures. The shape of the curves is not influenced by the addition of IL-g-POSS ${ }^{\circledR P h}$ but only shifted to higher values (Figure 4 ). The imaginary part of the relative permittivity values, $\varepsilon_{\mathrm{r}}{ }^{\prime \prime}$, shows a similar behavior at room temperature and above glass transition temperature. Figure $4 \mathrm{~b}$ shows just one broad transition with peaks located close to $-50{ }^{\circ} \mathrm{C}$ corresponding to $\beta$ relaxation associated to the motion of the hydroxyethyl units generated from the crosslinking reaction [80]. The starting of the increase from 30 to $50{ }^{\circ} \mathrm{C}$, depending on the system, is generally due to the relaxation processes of the main chains of the crosslinked epoxy network ( $\alpha$ relaxation). This relaxation is not well visible on the plots (Figure $4 b$ ) due to the important conduction phenomenon that gives an exponential variation towards higher values at the same temperature range. This relaxation arises from the fact that free charges are immobilized in the network and at sufficiently high temperatures, i.e., above $\mathrm{T}_{\mathrm{g}}$ of the polymer, the charges can migrate in the presence of an applied electric field. As the temperature increases above the glass transition temperature, the conductivity of the system increases giving rise to the increase of the concentration of charge carriers [81]. This increase of the dielectric constant can be explained by (i) the nanoscale dispersion of IL-g-POSS ${ }^{\circledR P h}$ nanoclusters inside the epoxy matrix leading to limited free volume, and by (ii) the increased polarizability of the resulting hybrid nanomaterials since they have the highest ionic liquid content (cation/anion). This allows the formation of conductive interfacial layers around aggregated POSS ${ }^{\circledR P h}$, i.e., a potential conductive path. Hence, the development of ILM/IPD/IL-g-POSS ${ }^{\circledR P h}$ nanomaterials with high dielectric constant is expected to find application as suitable electrolyte material.

The $\sigma_{\text {AC }}$ conductivity of the networks showed a linear increase with respect to frequency with a dependence equal to one at high frequencies. Frequency dependency follows the law (2):

$$
\sigma_{\mathrm{AC}}(\omega)=\omega^{\mathrm{s}}
$$

with $0 \leq \mathrm{s} \leq 1$ characterizing hopping conduction $[82,83]$. As the temperature increases, the conductivity becomes independent on the frequency and increases by 2 to 3 orders of magnitude for all the epoxy networks. A horizontal plateau appears progressively, expressing the thermal activation of the DC conductivity. The amplitude of this plateau corresponds to the DC conductivity at a given temperature. As the temperature increases, the mobility of the electrons increases shifting the plateau to higher frequencies and higher value of conductivity. The plateau appearing for different epoxy ILM/IPD and the corresponding hybrid $\mathrm{O} / \mathrm{I}$ networks seem to have the same influence with respect to frequency and temperature. A decrease of the conductivity values is observed at high temperatures and low frequencies, such as for ILM1/IPD, ILM2/IPD, and ILM2/IL.NTf 2 -g-POSS ${ }^{\circledR P h}$ over $120^{\circ} \mathrm{C}$ and $10^{2}$ $\mathrm{Hz}$. This can be attributed to the electrode polarization phenomenon leading to blocking electrodes [84]. Conductivity DC values are extrapolated before this decrease. As a result, the ionic conductivity for all investigated epoxy ionic liquids networks from the plateau region of each dielectric spectrum at room or high temperature follow the following order: ILM2/IPD/IL.NTf 2 -g-POSS ${ }^{\circledR P h}>$ ILM2/IPD/IL.Cl-g-POSS ${ }^{\circledR P h}>$ ILM1/IPD/IL.NTf $_{2}$-gPOSS $^{\circledR P h}>$ ILM1/IPD/IL.Cl-g-POSS ${ }^{\circledR P h}>$ ILM2/IPD > ILM1/IPD > DGEBA/IPD, which is the reverse order of $\mathrm{T}_{\mathrm{g}}$ shown in Figure 3. These results suggest that polymer chain relaxation plays a dominant role in ion transportation. Specifically, the ILM/IPD/IL-g-POSS ${ }^{\circledR P h}$ with $\mathrm{NTf}_{2}{ }^{-}$anions networks show significantly a higher ionic conductivity compared to the ILM/IPD/IL-g-POSS ${ }^{\circledR P h}$ with $\mathrm{Cl}^{-}$anion networks, indicating also a strong dependence of the conductivity on the identity of the counterion which coincides with the significantly 
lower $\mathrm{T}_{\mathrm{g}}$. This can be attributed to the difference in symmetry and size of the anions and to the dissociation energy of the ion pairs when the effects of $T_{g}$ are removed. Chen et al. [85] observed a similar effect on ionic conductivity in a PIL when they exchanged chloride $\left(\mathrm{Cl}^{-}\right)$anion with the bis(trifluoromethanesulfonyl)imide $\left(\mathrm{NTf}_{2}{ }^{-}\right)$anion. In addition, with increasing temperature, the difference of ionic conductivity between the ILM/IPD and their hybrid O/I networks with different anions decreases, suggesting that at high temperatures the importance of $\mathrm{T}_{\mathrm{g}}$ becomes less pronounced. Therefore, ionic conductivity values are

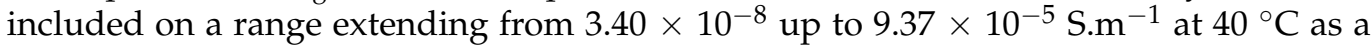
function of the system (Table 3 ). Moreover, for high temperatures above the $\mathrm{T}_{\mathrm{g}}$, ionic conductivity increased significantly to reach much higher values (see Table 3 and Figure 5).

Table 3. Ionic conductivity of the different epoxy ionic liquids networks at different temperatures.

\begin{tabular}{|c|c|c|c|c|}
\hline Samples & $\begin{array}{c}\sigma_{\mathrm{AC}} \\
@ 40^{\circ} \mathrm{C}\end{array}$ & $\begin{array}{c}\sigma_{\mathrm{AC}} \\
@ 50^{\circ} \mathrm{C}\end{array}$ & \begin{tabular}{c}
$\sigma_{\mathrm{AC}}$ \\
\hdashline $70^{\circ} \mathrm{C}$
\end{tabular} & $\begin{array}{c}\sigma_{\mathrm{AC}} \\
@ 100{ }^{\circ} \mathrm{C}\end{array}$ \\
\hline ILM1-IPD & $3.40 \times 10^{-8}$ & $1.15 \times 10^{-7}$ & $3.91 \times 10^{-6}$ & $3.12 \times 10^{-4}$ \\
\hline ILM1-IPD/IL.Cl-g-POSS ${ }^{\circledR P h}$ & $5.74 \times 10^{-6}$ & $3.46 \times 10^{-5}$ & $3.05 \times 10^{-4}$ & $1.63 \times 10^{-2}$ \\
\hline ILM1-IPD/IL.NTf ${ }_{2}$-g-POSS ${ }^{\circledR P h}$ & $2.11 \times 10^{-5}$ & $6.12 \times 10^{-5}$ & $6.28 \times 10^{-4}$ & $2.15 \times 10^{-2}$ \\
\hline ILM2-IPD & $5.42 \times 10^{-8}$ & $3.80 \times 10^{-6}$ & $2.08 \times 10^{-4}$ & $1.28 \times 10^{-3}$ \\
\hline ILM2-IPD/IL.Cl-g-POSS ${ }^{\circledR P h}$ & $2.54 \times 10^{-5}$ & $8.39 \times 10^{-5}$ & $1.19 \times 10^{-3}$ & $4.38 \times 10^{-2}$ \\
\hline ILM2-IPD/IL.NTf ${ }_{2}$-g-POSS ${ }^{\circledR P h}$ & $9.37 \times 10^{-5}$ & $9.81 \times 10^{-4}$ & $7.27 \times 10^{-3}$ & $6.84 \times 10^{-2}$ \\
\hline
\end{tabular}

Figure 6 presents the evolution of the DC conductivity of all the epoxy ionic liquid networks as a function of temperature extrapolated from dielectric spectroscopy measurements at $0.1 \mathrm{~Hz}$. The measured DC conductivity by dielectric spectroscopy has a linear slope above the glass transition temperature of epoxy for DGEBA/IPD (Figure S5), ILM/IPD and their epoxy hybrid O/I networks (Figure 6). All the slopes are well fitted with the Arrhenius (Equation (3)) law by exhibiting linear dependence, where the obtained Arrhenius 2-parameters, i.e., activation energies and infinite conductivity, $\sigma_{0}$, are presented in Table 4 calculated from the slope of the fitted curves in Figure 6.

$$
\sigma_{\mathrm{DC}}(\mathrm{T})=\sigma_{0} \exp \left(-\frac{E_{a}}{k_{B} T}\right)
$$

where $k_{B}$ is the Boltzmann's constant $\left(k_{B}=8.617 \times 10^{-5} \mathrm{eV} . \mathrm{K}^{-1}\right)$.

The R-square values confirm that the temperature dependence of ionic conductivity is very good in accordance with the Arrhenius equation. Conductivity increases with increasing temperature and follows Arrhenius dependence for all nanomaterials, resulting in an accelerated motion of polymer chains and promoting faster migration of ions at higher temperatures $[86,87]$. Thus, the mechanism of ionic conductivity can be understood from activation energy $\left(E_{a}\right)$.

A lower activation energy, $\mathrm{E}_{\mathrm{a}}$, means a better transmission conductor for DGEBA/IPD, ILM/IPD, and their hybrid O/I networks presented in Table 4. The activation energies are in the same range for the ILM1/IPD and ILM2/IPD networks and decrease for both with the addition of IL-g-POSS ${ }^{\circledR P h}$ whatever the anion nature. This signifies that the substitution of ILM1 with ILM2 affected neither the DC conductivity values nor the activation energy of the system. The lowest value of $\mathrm{E}_{\mathrm{a}}$ is for ILM/IPD/IL-g-POSS ${ }^{\circledR P h}$ networks as is observed in Table 4, and the highest ionic conductivities are also observed for the same networks as presented in Table 3. Compared to pure ILs, the activation energies for ionic conductivities with IL-g-POSS ${ }^{\circledR P h}$ nanoclusters (Table 4) are higher [86,87]. In fact, this behavior indicated that the introduction of IL-g-POSS ${ }^{\circledR P h}$ led to an increase of ion transportation due to the structural changes (clustering) in the network. This is due to decrease of $T_{g}$ of the ILM/IPD networks by addition of IL-g-POSS ${ }^{\circledR P h}$ and the presence of high amount of ionic liquid facilitating ionic movement in the matrix. As a result, all investigated epoxy ionic liquids 
materials displayed a very good ion transmission performance with the maximum ionic conductivity in the temperature range, from 40 to $80^{\circ} \mathrm{C}$.

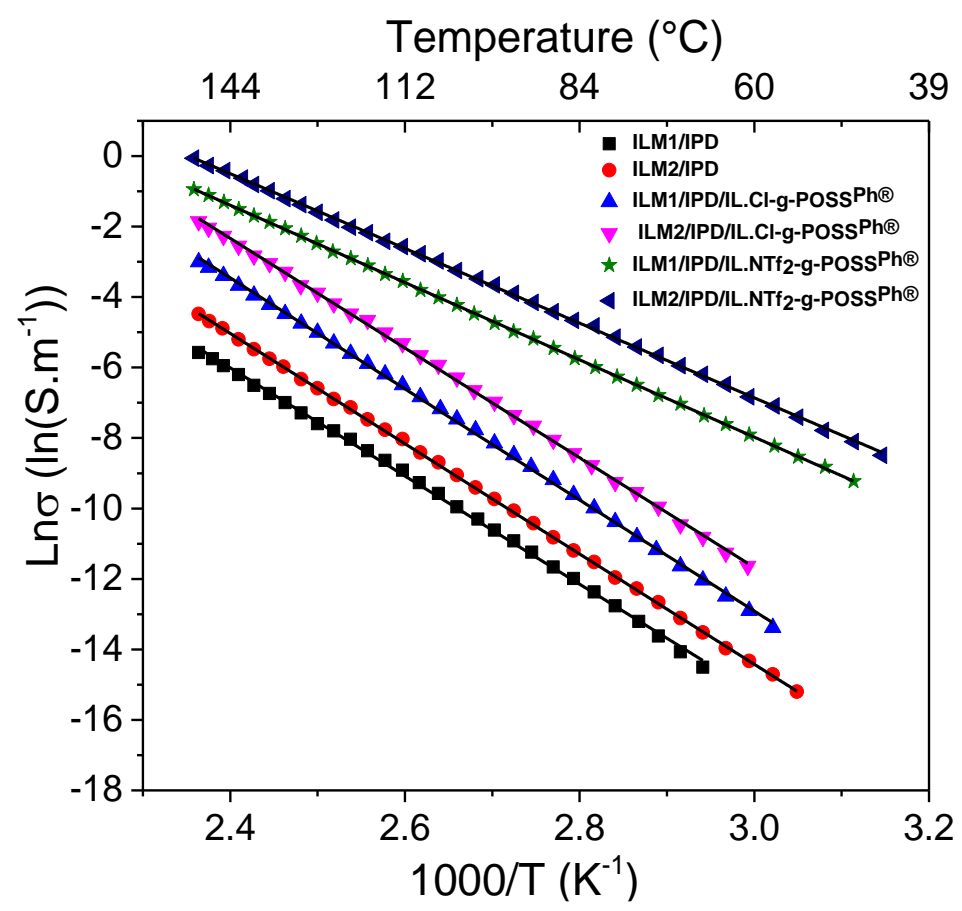

Figure 6. Dependence of DC conductivity with temperature (extrapolated from AC conductivity values at $0.1 \mathrm{~Hz}$ ). Solid black lines represent a regression to the Arrhenius equation.

Table 4. Arrhenius equation regression values of temperature dependent conductivity data at room temperature.

\begin{tabular}{|c|c|c|c|}
\hline Samples & $\begin{array}{c}\sigma_{0} \\
\left(S \cdot m^{-1}\right)\end{array}$ & $\begin{array}{c}E_{a} \\
(e V)\end{array}$ & R-Square \\
\hline ILM1-IPD & $4.87 \times 10^{13}$ & 1.36 & 0.99856 \\
\hline ILM1-IPD/IL.Cl-g-POSS ${ }^{\circledR P h}$ & $2.71 \times 10^{15}$ & 1.14 & 0.99612 \\
\hline ILM1-IPD/IL.NTf 2 -g-POSS ${ }^{\circledR P h}$ & $1.14 \times 10^{15}$ & 1.06 & 0.99712 \\
\hline ILM2-IPD & $6.15 \times 10^{13}$ & 1.35 & 0.99875 \\
\hline ILM2-IPD/IL.Cl-g-POSS ${ }^{\circledR P h}$ & $7.72 \times 10^{10}$ & 0.92 & 0.99436 \\
\hline ILM2-IPD/IL.NTf 2 -g-POSS ${ }^{\circledR P h}$ & $3.28 \times 10^{10}$ & 0.86 & 0.99236 \\
\hline
\end{tabular}

\section{Conclusions}

In this work, a new generation of epoxy hybrid organic/inorganic networks based on diepoxydized ionic liquid monomers (ILMs) and POSS ${ }^{\circledR P h}$ nanoclusters,-i.e., a non-fully condensed polyhedral oligomeric silsesquioxane (POSS ${ }^{\circledR P h}$-triol) or IL-modified POSS ${ }^{\circledR P h}$ combined with two different anions chloride $\left(\mathrm{Cl}^{-}\right)$or bis-trifluoromethanesulfonimidate $\left(\mathrm{NTf}_{2}{ }^{-}\right.$)-has been prepared. Either POSS ${ }^{\circledR P h}$-triol or IL-g-POSS ${ }^{\circledR P h}$ could generate crosslinks from a pre-reaction with the epoxy prepolymers, ILM1 or ILM2. The analysis of morphologies of hybrid nanomaterials was performed by transmission electron microscopy which evidenced well-dispersed POSS ${ }^{\circledR}$-aggregates-based nanostructured networks with nanometer scale particle size of POSS ${ }^{\circledR P h}$ aggregates in the epoxy ILM/IPD matrix. As a consequence, the nanostructured epoxy $\mathrm{O} / \mathrm{I}$ hybrids display a decrease of the glass transition as compared to the neat ILM/IPD networks. Nevertheless, changing the chemical architecture of ILMs monomers, the introduction of POSS ${ }^{\circledR P h}$-triol (ILM2/IPD) permits balancing the $\mathrm{T}_{\mathrm{g}}$ decrease (74 vs. $54^{\circ} \mathrm{C}$ ). The epoxy hybrid O/I networks display higher thermal stability and resistance to oxidation, especially the ILM2/IPD matrix. Moreover, these nanostructured materials display low surface energy $\left(18.2-20.7 \mathrm{~mJ} . \mathrm{m}^{-2}\right)$, high hydrophobicity $\left(\mathrm{H}_{2} \mathrm{O}\right.$ 
contact angle from 108 to $120^{\circ}$ ) and oleopophobicity (methylene diiodide contact angle from 75 to $92^{\circ}$ ) which make them promising materials for coating applications. Finally, the epoxy-LI (ILMs/IPD) networks loaded with IL-g-POSS ${ }^{\circledR P h}$ appear to be promising materials for reducing charge accumulation within insulation. They have the advantage of reaching interesting conductivities for low glass transition temperatures (around $70{ }^{\circ} \mathrm{C}$ ). The contribution is perceptible from temperatures well below the glass transition, with

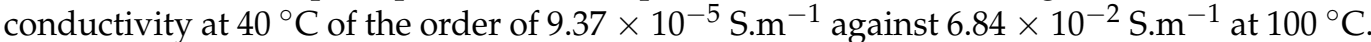
Although the charge carriers are not clearly identified, the improvement seems essentially of ionic origin. On the other hand, a thermal activation mechanism has been demonstrated. These results are promising for new solid polymer electrolytes.

Supplementary Materials: The following supporting information can be downloaded at: https: / / www.mdpi.com/article/10.3390/nano12030550/s1, Figure S1: DSC thermograms after curing of (a) ILM1/IPD and (b) ILM2/IPD; Figure S2: Epoxy group conversion as a function of the reaction time and during temperature steps from FT-IR for the epoxy O/I hybrid networks containing POSS ${ }^{\circledR P h}$ triol, IL.Cl-g-POSS ${ }^{\circledR P h}$ and IL.NTf2-g-POSS ${ }^{\circledR} \mathrm{Ph}$ respectively, prepared based on epoxy ionic liquids monomers: (a) ILM1, and (b) ILM2; Figure S3: HR-MAS ${ }^{13} \mathrm{C}-\mathrm{NMR}$ spectrum of the epoxy O/I hybrid networks containing POSS ${ }^{\circledR P h}$-triol, IL.Cl-g-POSS ${ }^{\circledR P h}$ and IL.NTf2-g-POSS ${ }^{\circledR}$ Ph respectively, prepared based on epoxy ionic liquids monomers: (a) ILM1, and (b) ILM2 (DMSO-d6; $400 \mathrm{MHz}$ ); Figure S4. Evolution of weight loss as a function of the temperature (TGA) and derivative of TGA curves (DTG) for the epoxy hybrid O/I networks containing POSS ${ }^{\circledR P h}$-triol, IL.Cl-g-POSS ${ }^{\circledR P h}$ and IL.NTf $_{2}$-g-POSS ${ }^{\circledR P h}$ respectively, prepared based on epoxy monomers: (a) ILM1, and (b) ILM2; Figure S6: Dependence of DC conductivity with temperature (extrapolated from AC conductivity values at $0.1 \mathrm{~Hz}$ for DGEBA/IPD network). Solid red line represents a regression to the Arrhenius equation.

Author Contributions: Conceptualization, S.L., J.D.-R. and J.-F.G.; methodology, H.C., S.L., J.D.-R. and J.-F.G.; software, H.C.; validation, S.L., J.D.-R. and J.-F.G.; formal analysis, H.C., S.L., J.D.-R. and J.-F.G.; investigation, H.C., S.L., J.D.-R. and J.-F.G.; resources, H.C., S.L., J.D.-R. and J.-F.G.; data curation, H.C., S.L., J.D.-R. and J.-F.G.; writing-original draft preparation, H.C., S.L., J.D.-R. and J.-F.G.; writing-review and editing S.L., J.D.-R. and J.-F.G.; supervision, S.L., J.D.-R. and J.-F.G.; project administration, S.L., J.D.-R. and J.-F.G.; funding acquisition, J.-F.G. All authors have read and agreed to the published version of the manuscript.

Funding: This research received no external funding.

Institutional Review Board Statement: Not applicable.

Informed Consent Statement: Not applicable.

Data Availability Statement: The data presented in this study are available on request from the corresponding author.

Conflicts of Interest: The authors declare no conflict of interest.

\section{References}

1. Guo, Q.; Han, Y.; Wang, H.; Xiong, S.; Sun, W.; Zheng, C.; Xie, K. Flame retardant and stable $\mathrm{Li}_{1.5} \mathrm{Al}_{0.5} \mathrm{Ge}_{1.5}\left(\mathrm{PO}_{4}\right)_{3}-\mathrm{supported}$ ionic liquid gel polymer electrolytes for high safety rechargeable solid-state lithium metal batteries. J. Phys. Chem. C 2018, 122, 10334-10342. [CrossRef]

2. $\quad$ Liu, Q.; Geng, Z.; Han, C.; Fu, Y.; Li, S.; He, Y.B.; Kang, F.; Li, B. Challenges and perspectives of garnet solid electrolytes for all solid-state lithium batteries. J. Power Sources 2018, 389, 120-134. [CrossRef]

3. Pandian, A.S.; Chen, X.C.; Chen, J.; Lokitz, B.S.; Ruther, R.E.; Yang, G.; Lou, K.; Nanda, J.; Delnick, F.M.; Dudney, N.J. Facile and scalable fabrication of polymer-ceramic composite electrolyte with high ceramic loadings. J. Power Sources 2018, 390, 153-164. [CrossRef]

4. Wang, A.; Liu, X.; Wang, S.; Chen, J.; Xu, H.; Xing, Q.; Zhang, L. Polymeric ionic liquid enhanced all-solid-state electrolyte membrane for high-performance lithium-ion batteries. Electrochim. Acta 2018, 276, 184-193. [CrossRef]

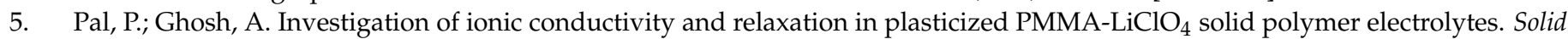
State Ion. 2018, 319, 117-124. [CrossRef]

6. Ban, X.; Zhang, W.; Chen, N.; Sun, C. A high-performance and durable poly (ethylene oxide)-based composite solid electrolyte for all solid-state lithium battery. J. Phys. Chem. C 2018, 122, 9852-9858. [CrossRef] 
7. Manthiram, A.; Yu, X.; Wang, S. Lithium battery chemistries enabled by solid-state electrolytes. Nat. Rev. Mater. 2017, 2, 1-16. [CrossRef]

8. Bouchet, R.; Maria, S.; Meziane, R.; Aboulaich, A.; Lienafa, L.; Bonnet, J.-P.; Phan, J.T.N.; Bertin, D.; Gigmes, D.; Devaux, D. Single-ion BAB triblock copolymers as highly efficient electrolytes for lithium-metal batteries. Nat. Mater. 2013, 12, $452-457$. [CrossRef]

9. Devaux, D.; Bouchet, R.; Glé, D.; Denoyel, R. Mechanism of ion transport in PEO/LiTFSI complexes: Effect of temperature, molecular weight and end groups. Solid State Ion. 2012, 227, 119-127. [CrossRef]

10. Appetecchi, G.; Hassoun, J.; Scrosati, B.; Croce, F.; Cassel, F.; Salomon, M. Hot-pressed, solvent-free, nanocomposite, PEO-based electrolyte membranes: II. All solid-state Li/LiFePO4 polymer batteries. J. Power Sources 2003, 124, 246-253. [CrossRef]

11. Yang, X.; Zhang, F.; Zhang, L.; Zhang, T.; Huang, Y.; Chen, Y. A high-performance graphene oxide-doped ion gel as gel polymer electrolyte for all-solid-state supercapacitor applications. Adv. Funct. Mater. 2013, 23, 3353-3360. [CrossRef]

12. Zhang, Z.; Sherlock, D.; West, R.; West, R.; Amine, K.; Lyons, L.J. Cross-linked network polymer electrolytes based on a polysiloxane backbone with oligo (oxyethylene) side chains: Synthesis and conductivity. Macromolecules 2003, 36, 9176-9180 [CrossRef]

13. MacGlashan, G.S.; Andreev, Y.G.; Bruce, P.G. Structure of the polymer electrolyte poly (ethylene oxide) 6: LiAsF 6 . Nature 1999, 398, 792-794. [CrossRef]

14. Yuan, C.; Li, J.; Han, P.; Lai, Y.; Zhang, Z.; Liu, J. Enhanced electrochemical performance of poly (ethylene oxide) based composite polymer electrolyte by incorporation of nano-sized metal-organic framework. J. Power Sources 2013, 240, 653-658. [CrossRef]

15. Gerbaldi, C.; Nair, J.R.; Kulandainathan, M.A.; Kumar, R.S.; Ferrara, C.; Mustarelli, P.; Stephan, A.M. Innovative high performing metal organic framework (MOF)-laden nanocomposite polymer electrolytes for all-solid-state lithium batteries. J. Mater. Chem. A 2014, 2, 9948-9954. [CrossRef]

16. Ren, Y.; Chen, K.; Chen, R.; Liu, T.; Zhang, Y.; Nan, C.W. Oxide electrolytes for lithium batteries. J. Am. Ceram. Soc. 2015, 98, 3603-3623. [CrossRef]

17. Wu, Z.; Xie, Z.; Yoshida, A.; Wang, Z.; Hao, X.; Abudula, A.; Guan, G. Utmost limits of various solid electrolytes in all-solid-state lithium batteries: A critical review. Renew. Sustain. Energy Rev. 2019, 109, 367-385. [CrossRef]

18. Yuan, J.; Mecerreyes, D.; Antonietti, M. Poly (ionic liquid) s: An update. Prog. Polym. Sci. 2013, 38, 1009-1036. [CrossRef]

19. Marcilla, R.; Alcaide, F.; Sardon, H.; Pomposo, J.A.; Pozo-Gonzalo, C.; Mecerreyes, D. Tailor-made polymer electrolytes based upon ionic liquids and their application in all-plastic electrochromic devices. Electrochem. Commun. 2006, 8, 482-488. [CrossRef]

20. Mecerreyes, D. Polymeric ionic liquids: Broadening the properties and applications of polyelectrolytes. Prog. Polym. Sci. 2011, 36, 1629-1648. [CrossRef]

21. Yuan, J.; Antonietti, M. Poly (ionic liquid) s: Polymers expanding classical property profiles. Polymer 2011, 52, 1469-1482. [CrossRef]

22. Obadia, M.M.; Mudraboyina, B.P.; Serghei, A.; Montarnal, D.; Drockenmuller, E. Reprocessing and recycling of highly cross-linked ion-conducting networks through transalkylation exchanges of C-N bonds. J. Am. Chem. Soc. 2015, 137, 6078-6083. [CrossRef]

23. Obadia, M.M.; Mudraboyina, B.P.; Serghei, A.; Phan, T.N.; Gigmes, D.; Drockenmuller, E. Enhancing properties of anionic poly (ionic liquid) s with 1, 2, 3-triazolium counter cations. ACS Macro Lett. 2014, 3, 658-662. [CrossRef]

24. Porcarelli, L.; Vlasov, P.S.; Ponkratov, D.O.; Lozinskaya, E.I.; Antonov, D.Y.; Nair, J.R.; Gerbaldi, C.; Mecerreyes, D.; Shaplov, A.S. Design of ionic liquid like monomers towards easy-accessible single-ion conducting polymer electrolytes. Eur. Polym. J. 2018, 107, 218-228. [CrossRef]

25. Wang, X.; Zhu, H.; Girard, G.M.; Yunis, R.; MacFarlane, D.R.; Mecerreyes, D.; Bhattacharyya, A.J.; Howlett, P.C.; Forsyth, M. Preparation and characterization of gel polymer electrolytes using poly (ionic liquids) and high lithium salt concentration ionic liquids. J. Mater. Chem. A 2017, 5, 23844-23852. [CrossRef]

26. Armand, M.; Endres, F.; MacFarland, D.R.; Ohno, H.; Scrosati, B. Ionic-liquid materials for the electrochemical challenges of the future. Nat. Mater. 2009, 8, 621-629. [CrossRef]

27. Ohno, H. Design of Ion Conductive Polymers Based on Ionic Liquids. Macromol. Symp. 2007, 249-250, 551-556. [CrossRef]

28. Livi, S.; Chardin, C.; Lins, L.C.; Halawani, N.; Pruvost, S.; Duchet-Rumeau, J.; Gérard, J.F.; Baudoux, J. From Ionic Liquid Epoxy Monomer to Tunable Epoxy-Amine Network: Reaction Mechanism and Final Properties. ACS Sustain. Chem. Eng. 2019, 7, 3602-3613. [CrossRef]

29. Jung, G.Y.; Choi, J.H.; Lee, J.K. Thermal behavior and ion conductivity of polyethylene oxide/polyhedral oligomeric silsesquioxane nanocomposite electrolytes. Adv. Polym. Tech. 2015, 34, 21499. [CrossRef]

30. Lu, Q.; Dong, L.; Chen, L.; Fu, J.; Shi, L.; Li, M.; Zeng, X.; Lei, H.; Zheng, F. Inorganic-organic gel electrolytes with 3D cross-linking star-shaped structured networks for lithium ion batteries. Chem. Eng. J. 2020, 393, 124708. [CrossRef]

31. Laik, S.; Galy, J.; Gérard, J.F.; Monti, M.; Camino, G. Fire behaviour and morphology of epoxy matrices designed for composite materials processed by infusion. Polym. Degrad. Stab. 2016, 127, 44-55. [CrossRef]

32. Wu, Q.; Zhang, C.; Liang, R.; Wang, B. Combustion and thermal properties of epoxy/phenyltrisilanol polyhedral oligomeric silsesquioxane nanocomposites. J. Therm. Anal. Calorim. 2010, 100, 1009-1015. [CrossRef]

33. Zhang, W.; Camino, G.; Yang, R. Polymer/polyhedral oligomeric silsesquioxane (POSS ${ }^{\circledR}$ ) nanocomposites: An overview of fire retardance. Prog. Polym. Sci. 2017, 67, 77-125. [CrossRef] 
34. Wang, L.; Zheng, S. Surface morphology and dewettability of self-organized thermosets involving epoxy and POSS ${ }^{\circledR}$-capped poly (ethylene oxide) telechelics. Mater. Chem. Phys. 2012, 136, 744-754. [CrossRef]

35. Zeng, K.; Zheng, S. Nanostructures and surface dewettability of epoxy thermosets containing hepta (3, 3, 3-trifluoropropyl) polyhedral oligomeric silsesquioxane-capped poly (ethylene oxide). J. Phys. Chem. B 2007, 111, 13919-13928. [CrossRef]

36. Mishra, K.; Pandey, G.; Singh, R.P. Enhancing the mechanical properties of an epoxy resin using polyhedral oligomeric silsesquioxane $\left(\right.$ POSS $^{\circledR}$ ) as nano-reinforcement. Polym. Test. 2017, 62, 210-218. [CrossRef]

37. Peng, W.; Xu, S.; Li, L.; Zhang, C.; Zheng, S. Organic-inorganic nanocomposites via self-assembly of an amphiphilic triblock copolymer bearing a Poly (butadiene-g-POSS ${ }^{\circledR}$ ) subchain in epoxy thermosets: Morphologies, surface hydrophobicity, and dielectric properties. J. Phys. Chem. B 2016, 120, 12003-12014. [CrossRef]

38. Chinnam, P.R.; Wunder, S.L. Polyoctahedral silsesquioxane-nanoparticle electrolytes for lithium batteries: POSS ${ }^{\circledR}$-lithium salts and POSS ${ }^{\circledR}$-PEGs. Chem. Mater. 2011, 23, 5111-5121. [CrossRef]

39. Devaux, D.; Villaluenga, I.; Bhatt, M.; Shah, D.; Chen, X.C.; Thelen, J.L.; DeSimone, J.M.; Balsara, N.P. Crosslinked perfluoropolyether solid electrolytes for lithium ion transport. Solid State Ion. 2017, 310, 71-80. [CrossRef]

40. Yang, G.; Song, Y.; Wang, Q.; Zhang, L.; Deng, L. Review of ionic liquids containing, polymer/inorganic hybrid electrolytes for lithium metal batteries. Mater. Des. 2020, 190, 108563. [CrossRef]

41. Yang, G.; Chanthad, C.; Oh, H.; Ayhan, I.A.; Wang, Q. Organic-inorganic hybrid electrolytes from ionic liquid-functionalized octasilsesquioxane for lithium metal batteries. J. Mater. Chem. A 2017, 5, 18012-18019. [CrossRef]

42. Yang, G.; Oh, H.; Chanthad, C.; Wang, Q. Dumbbell-shaped octasilsesquioxanes functionalized with ionic liquids as hybrid electrolytes for lithium metal batteries. Chem. Mater. 2017, 29, 9275-9283. [CrossRef]

43. Na, W.; Lee, A.S.; Lee, J.H.; Hong, S.M.; Kim, E.; Koo, C.M. Hybrid ionogel electrolytes with POSS ${ }^{\circledR}$ epoxy networks for high temperature lithium ion capacitors. Solid State Ion. 2017, 309, 27-32. [CrossRef]

44. Chabane, H.; Livi, S.; Benes, H.; Ladavière, C.; Ecorchard, P.; Duchet-Rumeau, J.; Gérard, J.F. Polyhedral oligomeric silsesquioxanesupported ionic liquid for designing nanostructured hybrid organic-inorganic networks. Eur. Polym. J. 2019, 114, $332-337$. [CrossRef]

45. Chabane, H.; Livi, S.; Morelle, X.P.; Sonnier, R.; Dumazert, L.; Duchet-Rumeau, J.; Gerard, J.F. Synthesis of New Ionic LiquidGrafted Metal-Oxo Nanoclusters-Design of Nanostructured Hybrid Organic-Inorganic Polymer Networks. Polymer 2021, 224, 123721. [CrossRef]

46. Radchenko, A.V.; Chabane, H.; Demir, B.; Searles, D.J.; Duchet-Rumeau, J.; Gerard, J.F.; Baudoux, J.; Livi, S. New Epoxy Thermosets Derived from Bisimidazolium Ionic Liquid Monomer: An Experimental and Modelling Investigation. ACS Sustain. Chem. Eng. 2020, 8, 12208-12221. [CrossRef]

47. Radchenko, A.V.; Duchet-Rumeau, J.; Gérard, J.F.; Baudoux, J.; Livi, S. Cycloaliphatic epoxidized ionic liquids as new versatile monomers for the development of shape memory PIL networks by 3D printing. Polym. Chem. 2020, 11, 5475-5483. [CrossRef]

48. Owens, D.K.; Wendt, R. Estimation of the surface free energy of polymers. J. Appl. Polym. Sci. 1969, 13, 1741-1747. [CrossRef]

49. Ni, Y.; Zheng, S. Epoxy resin containing octamaleimidophenyl polyhedral oligomeric silsesquioxane. Macromol. Chem. Phys. 2005, 206, 2075-2083. [CrossRef]

50. Ni, Y.; Zheng, S.; Nie, K. Morphology and thermal properties of inorganic-organic hybrids involving epoxy resin and polyhedral oligomeric silsesquioxanes. Polymer 2004, 45, 5557-5568. [CrossRef]

51. Ababsa, H.S.; Safidine, Z.; Mekki, A.; Grohens, Y.; Ouadah, A.; Chabane, H. Fire behavior of flame-retardant polyurethane semi-rigid foam in presence of nickel (II) oxide and graphene nanoplatelets additives. J. Polym. Res. 2021, 28, 1-14. [CrossRef]

52. Greaves, T.L.; Drummond, C.J. Solvent nanostructure, the solvophobic effect and amphiphile self-assembly in ionic liquids. Chem. Soc. Rev. 2013, 42, 1096-1120. [CrossRef] [PubMed]

53. He, Z.; Alexandridis, P. Nanoparticles in ionic liquids: Interactions and organization. Phys. Chem. Chem. Phys. 2015, 17, 18238-18261. [CrossRef]

54. Maka, H.; Spychaj, T.; Pilawka, R. Epoxy resin/ionic liquid systems: The influence of imidazolium cation size and anion type on reactivity and thermomechanical properties. Ind. Eng. Chem. Res. 2012, 51, 5197-5206. [CrossRef]

55. Ueno, K.; Watanabe, M. From colloidal stability in ionic liquids to advanced soft materials using unique media. Langmuir 2011, 27, 9105-9115. [CrossRef] [PubMed]

56. Fonseca, G.S.; Machado, G.; Teixeira, S.R.; Fecher, G.H.; Morais, J.; Alves, M.C.; Dupont, J. Synthesis and characterization of catalytic iridium nanoparticles in imidazolium ionic liquids. J. Colloid Interface Sci. 2006, 301, 193-204. [CrossRef]

57. Zhou, Y.; Antonietti, M. Synthesis of very small $\mathrm{TiO}_{2}$ nanocrystals in a room-temperature ionic liquid and their self-assembly toward mesoporous spherical aggregates. J. Am. Chem. Soc. 2003, 125, 14960-14961. [CrossRef]

58. Shim, Y.; Kim, H.J. Solvation of carbon nanotubes in a room-temperature ionic liquid. ACS Nano 2009, 3, 1693-1702. [CrossRef]

59. Tokuda, H.; Hayamizu, K.; Ishii, K.; Susan, M.A.B.H.; Watanabe, M. Physicochemical properties and structures of room temperature ionic liquids. 2. Variation of alkyl chain length in imidazolium cation. J. Phys. Chem. B 2005, 109, 6103-6110. [CrossRef]

60. Donato, R.; Perchacz, M.; Ponyrko, S.; Donato, K.; Schrekker, H.; Beneš, H.; Matějka, L. Epoxy-silica nanocomposite interphase control using task-specific ionic liquids via hydrolytic and non-hydrolytic sol-gel processes. RSC Adv. 2015, 5, 91330-91339. [CrossRef] 
61. Perchacz, M.; Donato, R.K.; Seixas, L.; Zhigunov, A.; Konefał, R.; Serkis-Rodzeń, M.; Beneš, H. Ionic Liquid-Silica Precursors via Solvent-Free Sol-Gel Process and Their Application in Epoxy-Amine Network: A Theoretical/Experimental Study. ACS Appl. Mate. Interfaces 2017, 9, 16474-16487. [CrossRef]

62. Li, G.Z.; Wang, L.; Toghiani, H.; Daulton, T.L.; Koyama, K.; Pittman, C.U. Viscoelastic and mechanical properties of epoxy/multifunctional polyhedral oligomeric silsesquioxane nanocomposites and epoxy/ladderlike polyphenylsilsesquioxane blends. Macromolecules 2001, 34, 8686-8693. [CrossRef]

63. Liu, H.; Zheng, S.; Nie, K. Morphology and thermomechanical properties of organic-inorganic hybrid composites involving epoxy resin and an incompletely condensed polyhedral oligomeric silsesquioxane. Macromolecules 2005, 38, 5088-5097. [CrossRef]

64. Deng, Y.; Bernard, J.; Alcouffe, P.; Galy, J.; Dai, L.; Gérard, J.F. Nanostructured hybrid polymer networks from in situ self-assembly of RAFT-synthesized POSS ${ }^{\circledR}$-based block copolymers. J. Polym. Sci. Part A: Polym. Chem. 2011, 49, 4343-4352. [CrossRef]

65. Abad, M.J.; Barral, L.; Fasce, D.P.; Williams, R.J. Epoxy networks containing large mass fractions of a monofunctional polyhedral oligomeric silsesquioxane (POSS ${ }^{\circledR}$ ). Macromolecules 2003, 36, 3128-3135. [CrossRef]

66. Zucchi, I.A.; Galante, M.J.; Williams, R.J.; Franchini, E.; Galy, J.; Gérard, J.F. Monofunctional epoxy-POSS ${ }^{\circledR}$ dispersed in epoxyamine networks: Effect of a prereaction on the morphology and crystallinity of POSS ${ }^{\circledR}$ domains. Macromolecules 2007, 40 , 1274-1282. [CrossRef]

67. Cartier, H.; Chopin, A.; Perego, C. Radiation Crosslinking of Halogen-Free Flame Retardant Polymer. International Patent Application No. WO2007106074A2. U.S. Patent 7,423,080, 3 March 2007.

68. Wang, X.; Hu, Y.; Song, L.; Xing, W.; Lu, H. Thermal degradation behaviors of epoxy resin/POSS ${ }^{\circledR}$ hybrids and phosphorus-silicon synergism of flame retardancy. J. Polym. Sci. Part B: Polym. Phys. 2010, 48, 693-705. [CrossRef]

69. Zanetti, M.; Camino, G.; Canavese, D.; Morgan, A.B.; Lamelas, F.J.; Wilkie, C.A. Fire retardant halogen- antimony-clay synergism in polypropylene layered silicate nanocomposites. Chem. Mater. 2002, 14, 189-193. [CrossRef]

70. Bizet, S.; Galy, J.; Gérard, J.F. Structure-property relationships in organic-inorganic nanomaterials based on methacryl-POSS ${ }^{\circledR}$ and dimethacrylate networks. Macromolecules 2006, 39, 2574-2583. [CrossRef]

71. Hirata, T.; Kashiwagi, T.; Brown, J.E. Thermal and oxidative degradation of poly (methyl methacrylate): Weight loss. Macromolecules 1985, 18, 1410-1418. [CrossRef]

72. Mantz, R.; Jones, P.; Chaffee, K.; Lichtenhan, J.; Gilman, J.; Ismail, I.; Burmeister, M. Thermolysis of polyhedral oligomeric silsesquioxane (POSS ${ }^{\circledR}$ ) macromers and POSS ${ }^{\circledR}$-siloxane copolymers. Chem. Mater. 1996, 8, 1250-1259. [CrossRef]

73. Tomczak, S.J.; Marchant, D.; Svejda, S.; Minton, T.K.; Brunsvold, A.L.; Gouzman, I.; Grossman, E.; Schatz, G.C.; Troya, D.; Sun, L. Properties and improved space survivability of POSS ${ }^{\circledR}$ (polyhedral oligomeric silsesquioxane) polyimides. MRS Online Proc. Libr. (OPL) 2004, 851, 395-406. [CrossRef]

74. Badey, J.; Espuche, E.; Sage, D.; Chabert, B.; Jugnet, Y.; Batier, C.; Duc, T.M. A comparative study of the effects of ammonia and hydrogen plasma downstream treatment on the surface modification of polytetrafluoroethylene. Polymer 1996, 37, 1377-1386. [CrossRef]

75. Włoch, J.; Terzyk, A.P.; Wiśniewski, M.; Kowalczyk, P. Nanoscale water contact angle on Polytetrafluoroethylene surfaces characterized by molecular Dynamics-Atomic force microscopy imaging. Langmuir 2018, 34, 4526-4534. [CrossRef] [PubMed]

76. Kim, K.; Lichtenhan, J.D.; Otaigbe, J.U. Facile route to nature inspired hydrophobic surface modification of phosphate glass using polyhedral oligomeric silsesquioxane with improved properties. Appl. Surf. Sci. 2019, 470, 733-743. [CrossRef]

77. Almeida, H.F.; Lopes-da-Silva, J.A.; Freire, M.G.; Coutinho, J.A. Surface tension and refractive index of pure and water-saturated tetradecyltrihexylphosphonium-based ionic liquids. J. Chem. Thermodyn. 2013, 57, 372-379. [CrossRef]

78. Carvalho, P.J.; Neves, C.M.; Coutinho, J.A. Surface tensions of bis (trifluoromethylsulfonyl) imide anion-based ionic liquids. J. Chem. Eng. Data 2010, 55, 3807-3812. [CrossRef]

79. Kaur, M.; Singh, G.; Kumar, S.; Kang, T.S. Thermally stable microemulsions comprising imidazolium based surface active ionic liquids, non-polar ionic liquid and ethylene glycol as polar phase. J. Colloid Interface Sci. 2018, 511, 344-354. [CrossRef] [PubMed]

80. Heux, L.; Halary, J.; Lauprêtre, F.; Monnerie, L. Dynamic mechanical and 13C NMR investigations of molecular motions involved in the $\beta$ relaxation of epoxy networks based on DGEBA and aliphatic amines. Polymer 1997, 38, 1767-1778. [CrossRef]

81. Halawani, N.; Augé, J.L.; Morel, H.; Gain, O.; Pruvost, S. Electrical, thermal and mechanical properties of poly-etherimide epoxy-diamine blend. Compo. B. Eng. 2017, 110, 530-541. [CrossRef]

82. Dyre, J.C.; Schrøder, T.B. Universality of ac conduction in disordered solids. Rev. Mod. Phys. 2000, 72, 873. [CrossRef]

83. Psarras, G. Hopping conductivity in polymer matrix-metal particles composites. Compos. Part A: Appl. Sci. Manuf. 2006, 37, 1545-1553. [CrossRef]

84. Emmert, S.; Wolf, M.; Gulich, R.; Krohns, S.; Kastner, S.; Lunkenheimer, P.; Loidl, A. Electrode polarization effects in broadband dielectric spectroscopy. Eur. Phys. J. B. 2011, 83, 157-165. [CrossRef]

85. Chen, H.; Choi, J.H.; Salas-de la Cruz, D.; Winey, K.I.; Elabd, Y.A. Polymerized ionic liquids: The effect of random copolymer composition on ion conduction. Macromolecules 2009, 42, 4809-4816. [CrossRef]

86. Hemp, S.T.; Zhang, M.; Allen, M.H., Jr.; Cheng, S.; Moore, R.B.; Long, T.E. Comparing ammonium and phosphonium polymerized ionic liquids: Thermal analysis, conductivity, and morphology. Macromol. Chem. Phys. 2013, 214, 2099-2107. [CrossRef]

87. Ye, Y.; Elabd, Y.A. Anion exchanged polymerized ionic liquids: High free volume single ion conductors. Polymer 2011, 52, 1309-1317. [CrossRef] 